\title{
Ultrathin SnO2 nanosheets: Oriented attachment mechanism, nonstoichiometric defects and enhanced Lithium-ion battery performances.
}

Wang, Cen; Du, Gaohui; Ståhl, Kenny; Huang, Haixiao; Zhong, Yijun; Jiang, J.Z.

Published in:

Journal of Physical Chemistry Part C: Nanomaterials and Interfaces

Link to article, DOI:

10.1021/jp300136p

Publication date:

2012

Document Version

Publisher's PDF, also known as Version of record

Link back to DTU Orbit

Citation (APA):

Wang, C., Du, G., Ståhl, K., Huang, H., Zhong, Y., \& Jiang, J. Z. (2012). Ultrathin SnO nanosheets: Oriented attachment mechanism, nonstoichiometric defects and enhanced Lithium-ion battery performances. Journal of Physical Chemistry Part C: Nanomaterials and Interfaces, 116, 4000-4011. https://doi.org/10.1021/jp300136p

\section{General rights}

Copyright and moral rights for the publications made accessible in the public portal are retained by the authors and/or other copyright owners and it is a condition of accessing publications that users recognise and abide by the legal requirements associated with these rights.

- Users may download and print one copy of any publication from the public portal for the purpose of private study or research.

- You may not further distribute the material or use it for any profit-making activity or commercial gain

- You may freely distribute the URL identifying the publication in the public portal 


\title{
Ultrathin $\mathrm{SnO}_{2}$ Nanosheets: Oriented Attachment Mechanism, Nonstoichiometric Defects, and Enhanced Lithium-Ion Battery Performances
}

\author{
Cen Wang, ${ }^{\dagger}$ Gaohui Du, ${ }^{\ddagger}$ Kenny Ståhl, ${ }^{\S}$ Haixiao Huang, ${ }^{\dagger}$ Yijun Zhong, ${ }^{\ddagger}$ and J. Z. Jiang* ${ }^{*}{ }^{\dagger}$ \\ ${ }^{\dagger}$ International Center for New-Structured Materials (ICNSM), Zhejiang University and Laboratory of New-Structured Materials, \\ Department of Materials Science \& Engineering, Zhejiang University, Hangzhou 310027, P. R. China \\ ${ }^{\ddagger}$ Institute of Physical Chemistry, Zhejiang Normal University, Jinhua 321004, P. R. China \\ ${ }^{\S}$ Department of Chemistry, Building 207, Technical University of Denmark, DK-2800 Lyngby, Denmark
}

Supporting Information

\begin{abstract}
We successfully synthesized large-scale and highly pure ultrathin $\mathrm{SnO}_{2}$ nanosheets (NSs), with a minimum thickness in the regime of ca. $2.1 \mathrm{~nm}$ as determined by HRTEM and in good agreement with XRD refinements and AFM height profiles. Through TEM and HRTEM observations on time-dependent samples, we found that the asprepared $\mathrm{SnO}_{2}$ NSs were assembled by “oriented attachment" of preformed $\mathrm{SnO}_{2}$ nanoparticles (NPs). Systematic trials showed that well-defined ultrathin $\mathrm{SnO}_{2} \mathrm{NSs}$ could only be obtained under appropriate reaction time, solvent, additive, precursor concentration, and cooling rate. A certain degree of nonstoichiometry appears inevitable in the well-defined $\mathrm{SnO}_{2} \mathrm{NSs}_{s}$ sample. However, deviations from the optimal synthetic parameters give rise to severe nonstoichiometry in the products, resulting in the formation of $\mathrm{Sn}_{3} \mathrm{O}_{4}$ or $\mathrm{SnO}$. This finding may open new accesses to the fundamental investigations of tin oxides as well as their intertransition processes. Finally, we investigated the lithium-ion storage of the $\mathrm{SnO}_{2} \mathrm{NSs}$ as compared to $\mathrm{SnO}_{2}$ hollow spheres and NPs. The results showed superior performance of $\mathrm{SnO}_{2} \mathrm{NSs}$ sample over its two counterparts. This greatly enhanced Li-ion storage capability of $\mathrm{SnO}_{2} \mathrm{NSs}$ is probably resulting from the ultrathin thicknesses and the unique porous structures: the nanometer-sized networks provide negligible diffusion times of ions thus faster phase transitions, while the "breathable" interior porous structure can effectively buffer the drastic volume changes during lithiation and delithiation reactions.
\end{abstract}

\section{INTRODUCTION}

Nowadays, the fast development and demand in industry intensively focus on various applications of nanomaterials. The main interest lies in more rational design and precise control over specialized morphologies of nanomaterials with tailored properties. Among various nanostructures, dimensionality is one of the most defining parameters which significantly control the ways in which materials behave. Until now, 0-D (quantum dots), 1-D (nanowires, nanotubes, nanorods), and 3-D crystals are abundantly documented, while 2-D structures are far less reported. Ever since the finding of graphene, ${ }^{1-3}$ the combination of unique molecular geometry with exciting properties triggered intensive efforts in synthesizing other 2D ultrathin nanosheet materials. ${ }^{4-11}$ Furthermore, 3-D hierarchical structures produced by self-assembly and higher order organization of nanosheet building blocks attract extensive attention due to their collective optical, electrical, and magnetic properties since the complicated spatial arrangement can provide both extraordinarily high activated surface area and robustness. ${ }^{12-15}$ However, it is still highly desirable to develop facile and reliable synthesis routes, which do not require catalysts, expensive or toxic templates, and tedious procedures for rational design of those hierarchical structures.
Solution-based procedures (known as "bottom-up" approach) for the syntheses of nanomaterials are very promising to precisely control their sizes and morphologies. However, the crystallization from a solution is still not fully understood. Classical crystal growth mode has been used to interpret crystallization processes since about 100 years ago. It is represented by atom additions to preformed nuclei and dissolution of unstable phases with concomitantly reprecipitation of stable phases. Alternatively, a particle-based aggregation mode named "oriented attachment" mechanism was recently proposed by Penn and Banfield, in which secondary crystal could be achieved by irreversible and highly oriented attachments of primary particles. ${ }^{16,17}$ This mechanism has been confirmed in various systems and thought to be potentially active in anisotropic growth of novel nanocrystals. ${ }^{18-23}$ The driving force for this spontaneous procedure stems from the elimination of thermodynamically high energy surfaces. Crystallization in this mode is often characterized by sequential processes involving structural and compositional modifications of amorphous precursors and crystalline intermediates. $^{24,25}$

Received: January 5, 2012

Published: January 18, 2012 
Table 1. Conditions of Representative Experimental Conditions Investigated in This Work ${ }^{a}$

\begin{tabular}{|c|c|c|c|c|c|}
\hline sample & $\begin{array}{l}\text { reaction time } \\
\text { (h) }\end{array}$ & $\begin{array}{c}\text { precursor } \\
\left(\mathrm{SnCl}_{2} \cdot 2 \mathrm{H}_{2} \mathrm{O}\right) \text { concn }\end{array}$ & $\begin{array}{c}r \text { value }(\%) \\
\left(V_{\mathrm{EtOH}} / V_{\text {total }}\right)\end{array}$ & additive $(0.8 \mathrm{M})$ & structures and morphologies \\
\hline SA1 & 4 & 15.8 & 50 & $\mathrm{NH}_{3} \cdot \mathrm{H}_{2} \mathrm{O}$ & $\mathrm{SnO}_{2}+\mathrm{Sn}_{6} \mathrm{O}_{4}(\mathrm{OH})_{4}, \mathrm{NPs}^{b}$ \\
\hline SA2 & 5 & 15.8 & 50 & $\mathrm{NH}_{3} \cdot \mathrm{H}_{2} \mathrm{O}$ & $\mathrm{SnO}_{2}+\mathrm{Sn}_{6} \mathrm{O}_{4}(\mathrm{OH})_{4}, \mathrm{NPs}+\mathrm{NSs}^{c}$ \\
\hline SA3 & 6 & 15.8 & 50 & $\mathrm{NH}_{3} \cdot \mathrm{H}_{2} \mathrm{O}$ & well-defined ultrathin $\mathrm{SnO}_{2} \mathrm{NSs}$ \\
\hline SA4 & 24 & 15.8 & 50 & $\mathrm{NH}_{3} \cdot \mathrm{H}_{2} \mathrm{O}$ & $\mathrm{SnO}_{2} \mathrm{NSs}+$ trivial $\mathrm{Sn}_{3} \mathrm{O}_{4} \mathrm{NSs}$ \\
\hline SA5 & 48 & 15.8 & 50 & $\mathrm{NH}_{3} \cdot \mathrm{H}_{2} \mathrm{O}$ & $\mathrm{SnO}_{2} \mathrm{NSs}+$ trivial $\mathrm{Sn}_{3} \mathrm{O}_{4} \mathrm{NSs}$ \\
\hline SA6 & 6 & 15.8 & 0 & $\mathrm{NH}_{3} \cdot \mathrm{H}_{2} \mathrm{O}$ & $\mathrm{SnO}_{2}$ nanoplates $+\mathrm{NPs}$ \\
\hline SA7 & 6 & 15.8 & 25 & $\mathrm{NH}_{3} \cdot \mathrm{H}_{2} \mathrm{O}$ & $\mathrm{SnO}_{2} \mathrm{NSs}+$ trivial NPs \\
\hline SA8 & 6 & 15.8 & 75 & $\mathrm{NH}_{3} \cdot \mathrm{H}_{2} \mathrm{O}$ & $\mathrm{SnO}_{2} \mathrm{NPs}+$ trivial NSs \\
\hline SA9 & 6 & 15.8 & 100 & $\mathrm{NH}_{3} \cdot \mathrm{H}_{2} \mathrm{O}$ & $\mathrm{SnO}_{2}$ hollow spheres \\
\hline SA10 & 6 & 15.8 & 50 & none & $\mathrm{SnO}_{2} \mathrm{NPs}$ \\
\hline SA11 & 6 & 15.8 & 50 & urea & $\mathrm{SnO}_{2} \mathrm{NPs}+$ trivial $\mathrm{SnO}_{2} \mathrm{NSs}$ \\
\hline SA12 & 6 & 6.8 & 50 & $\mathrm{NH}_{3} \cdot \mathrm{H}_{2} \mathrm{O}$ & $\mathrm{SnO}_{2} \mathrm{NSs}$ without hierarchical structure \\
\hline SA13 & 6 & 31.6 & 50 & $\mathrm{NH}_{3} \cdot \mathrm{H}_{2} \mathrm{O}$ & $\mathrm{SnO}_{2} \mathrm{NSs}+$ unreacted $\mathrm{Sn}_{6} \mathrm{O}_{4}(\mathrm{OH})_{4}$ \\
\hline SA14 & 6 & $15.8\left(\mathrm{SnCl}_{4} \cdot 5 \mathrm{H}_{2} \mathrm{O}\right)$ & 50 & $\mathrm{NH}_{3} \cdot \mathrm{H}_{2} \mathrm{O}$ & $\mathrm{SnO}_{2} \mathrm{NPs}$ \\
\hline SA15 & 6 & 15.8 & 50 & $\mathrm{NH}_{3} \cdot \mathrm{H}_{2} \mathrm{O}+50 \mu \mathrm{L} \mathrm{H}_{2} \mathrm{O}_{2}$ & $\mathrm{SnO}_{2} \mathrm{NPs}$ \\
\hline
\end{tabular}

$\mathrm{SnO}_{2}$, due to its intrinsic nonstoichiometry from oxygen vacancies, is regarded as $n$-type semiconductor with wide band gap energy of $3.6 \mathrm{eV}$. So far, different structures ${ }^{26-32}$ have been investigated as well as their potential applications in gas sensors, ${ }^{33-37}$ spintronics, ${ }^{38,39}$ photocatalysis, ${ }^{40}$ and supercapacitors, ${ }^{41-43}$ etc. Specifically, it attracts worldwide attention as the next generation lithium-ion battery anode materials. $^{30,44-48}$ Recently, our group successfully synthesized a new $\mathrm{SnO}_{2}$ NSs structure by a template free and surfactant free onepot hydrothermal method. The as-obtained $\mathrm{SnO}_{2}$ nanostructures feature sheet-based hierarchical configurations with a BET surface area as high as $180 \mathrm{~m}^{2} / \mathrm{g}$. Furthermore, they were found to possess room-temperature ferromagnetism as well as being a potential anode alternative in lithium-ion syntheses. $49,50,119$ Syntheses of 2-D NSs structures of nonlayered metal oxides such as $\mathrm{SnO}_{2}$ and $\mathrm{TiO}_{2}$ are extremely challenging. Thus, it is of great importance to unveil the formation mechanism and applicable properties of the $\mathrm{SnO}_{2}$ NSs. Herein, we systematically examined the ultrathin $\mathrm{SnO}_{2} \mathrm{NSs}$ by X-ray diffraction (XRD), transmission electron microscopy (TEM), highresolution transmission electron microscopy (HRTEM), scanning electron microscopy (SEM), X-ray photoelectron spectroscopy (XPS), atomic force microscopy (AFM), ultraviolet-visible spectrophotometry (UV-vis), etc. It was found that these $\mathrm{SnO}_{2}$ NSs were formed by "oriented attachment" of initial NPs. AFM height profile and HRTEM cross-section images indicated the minimum thickness of about $2.1 \mathrm{~nm}$, leading to optical band gap energy of $4.7 \mathrm{eV}$. Besides, inherent nonstoichiometry resulting in intermediate tin oxides and $\mathrm{SnO}$ was further examined by both HRTEM images and XPS. Finally, we compared the lithium-ion storage of the $\mathrm{SnO}_{2} \mathrm{NSs}$ with $\mathrm{SnO}_{2}$ hollow spheres and NPs. The results showed quite enhanced performance of $\mathrm{SnO}_{2}$ NSs sample over its two counterparts.

\section{EXPERIMENTAL SECTION}

Materials Syntheses. All reagents were purchased from the indicated suppliers and used without any further purification: tin dichloride dihydrate $\left(\mathrm{SnCl}_{2} \cdot 2 \mathrm{H}_{2} \mathrm{O}\right.$, Alfa Aesar, 98\%), analytical grade ethanol, $\mathrm{NH}_{3} \cdot \mathrm{H}_{2} \mathrm{O}(25-28$ wt \%), and urea (98\%) (Sinopharm Chemical Reagent Co. Ltd.). In a typical experiment, $\mathrm{SnCl}_{2} \cdot 2 \mathrm{H}_{2} \mathrm{O}$ powder was added to a mixture of ethanol $(\mathrm{EtOH})$ and water with $r$ value $(\mathrm{EtOH}$ vol \% in the solvent of EtOH and water) $0-100 \%$, and the solution turned into a white turbid suspension. Afterward, sufficient mineralizer (i.e., $0.8 \mathrm{M} \mathrm{NH}_{3} \cdot \mathrm{H}_{2} \mathrm{O}$ or urea) was added to reach a $\mathrm{Sn}$ (II) concentration of $6.8-31.6 \mathrm{mM}$, and the solution color turned to darken yellow-white. The obtained yellow-white turbid suspension was magnetically stirred for $10 \mathrm{~min}$ before transferred to a Teflon-lined stainless steel autoclave and then heated in an electric oven at $120^{\circ} \mathrm{C}$ for a reaction time from 4 to $48 \mathrm{~h}$. After natural or fast cooling, the yellow product was harvested by centrifugation and dried at $50{ }^{\circ} \mathrm{C}$ overnight. The detailed experimental parameters about the reaction time $(t, 0-$ $48 \mathrm{~h}$ ), solvent ( $r$ value, $0-100 \%)$, additives $\left(\mathrm{NH}_{3} \cdot \mathrm{H}_{2} \mathrm{O}\right.$, urea), and precursor concentration $(c, 6.8-31.6 \mathrm{mM})$ for the corresponding structures and morphologies of the products are listed in Table 1. (The cooling rate of the autoclave in this table is default as rapid cooling using an ice-water bath.)

Materials Characterizations. The products were characterized by X-ray diffractometer PANalytical X'pert Pro using $\mathrm{Cu}$ $\mathrm{K} \alpha$ radiation $(\lambda=1.5416 \AA)$. Transmission electron microscopy (TEM) Philips FEI 200CX operated at $160 \mathrm{kV}$, high-resolution transmission electron microscopy (HRTEM) JEOL 2100F operated at $200 \mathrm{kV}$, and scanning electron microscopy (SEM) Hitachi S4800 operated at $5 \mathrm{kV}$. For Rietveld refinements a local variation of LHMP was used. ${ }^{51} \mathrm{X}$-ray photoelectron spectroscopy (XPS) analyses were performed using a Kratos Amicus spectrometer. The X-ray source was $\mathrm{Mg} \mathrm{K} \alpha$ with $1253.6 \mathrm{eV}$ operating at $12 \mathrm{kV}$ and $180 \mathrm{~W}$, under the pressure of $1 \times 10^{-6}$ Torr (pass energy of $75 \mathrm{eV}$ and overall resolution $\sim 1$ $\mathrm{eV})$. UV-vis absorption and reflectance spectra were measured on a Shimadzu UV-3150 spectrophotometer. AFM image was acquired under tapping mode on a Park System XE-100E at ambient conditions. Cyclic voltammetry was performed on $\mathrm{CHI} 550 \mathrm{C}$ using the voltage window of $2 \mathrm{~V}-10 \mathrm{mV}$ (versus $\mathrm{Li}$ / $\mathrm{Li}^{+}$) at a sweep rate of $0.1 \mathrm{mV} / \mathrm{s}$. Li-ion battery properties were measured by Land CT2001A.

Electrochemical Measurements. The electrochemical measurements were carried out using homemade button cells with lithium metal as the counter and reference electrodes at room temperature $\left(25{ }^{\circ} \mathrm{C}\right)$. The electrode consisted of active material $\left(\mathrm{SnO}_{2}\right)$, conductivity agent (acetylene black, Alfa Aesar), and polymer binder (poly(vinylidene difluoride), 
PVDF, Aldrich) by a weight ratio of 80:10:10. The active material loading in each electrode (about $15 \mathrm{~mm}$ in diameter) was typically $1-2 \mathrm{mg}$. The electrolyte was $1 \mathrm{M} \mathrm{LiPF}_{6}$ in a 50:50 mixture of ethylene carbonate and diethyl carbonate. Cell assembly was carried out in an Ar-filled glovebox with the concentrations of water vapor and oxygen below $1 \mathrm{ppm}$. The working electrode was measured at room temperature in the whole process. The cell was charged and discharged at a constant current of $0.2 \mathrm{C}(156 \mathrm{~mA} / \mathrm{g})$ and a fixed voltage window between $2 \mathrm{~V}$ and $10 \mathrm{mV}$.

\section{RESULTS AND DISCUSSION}

$\mathrm{Sn}_{6} \mathrm{O}_{4}(\mathrm{OH})_{4}$ Intermediate. In this experiment, we used $\mathrm{Sn}(\mathrm{II}) \mathrm{Cl}_{2}$ as the precursor, which eventually underwent oxidation to form $\mathrm{Sn}(\mathrm{IV}) \mathrm{O}_{2}$ under hydrothermal condition. Actually, before oxidized, $\mathrm{Sn}$ (II) was found to be in the form of hydroxide intermediate $\mathrm{Sn}(\mathrm{II})_{6} \mathrm{O}_{4}(\mathrm{OH})_{4}$, which was explicitly revealed by XRD (see Supporting Information, Figure S1). This $\mathrm{XRD}$ result indicated that, at ambient condition, the precursor $\mathrm{SnCl}_{2}$ mainly transformed into poorly crystallized $\mathrm{Sn}_{6} \mathrm{O}_{4}(\mathrm{OH})_{4}$ (Joint Committee on Powder Diffraction Standards (JCPDS) card No. 46-1486, space group: $P \overline{4} 2{ }_{1} c, a=7.9268 \AA, c=9.1025$ $\AA$ ) after sequentially mixing with ethanol, water, and $\mathrm{NH}_{3} \cdot \mathrm{H}_{2} \mathrm{O}$. Actually, even if $\mathrm{NH}_{3} \cdot \mathrm{H}_{2} \mathrm{O}$ was not added, $\mathrm{SnCl}_{2}$ would still react with water to form $\mathrm{Sn}_{6} \mathrm{O}_{4}(\mathrm{OH})_{4} \cdot{ }^{52,53}$ However, the addition of $\mathrm{NH}_{3} \cdot \mathrm{H}_{2} \mathrm{O}$ quite favored this transition judging from the severe darkening of suspension color (from white to dark yellow-white), thus leading to higher yield of $\mathrm{Sn}_{6} \mathrm{O}_{4}(\mathrm{OH})_{4}$.

Characterization of Ultrathin $\mathrm{SnO}_{2}$ NSs. Figure 1 displays a low-magnification TEM overview image of the as-

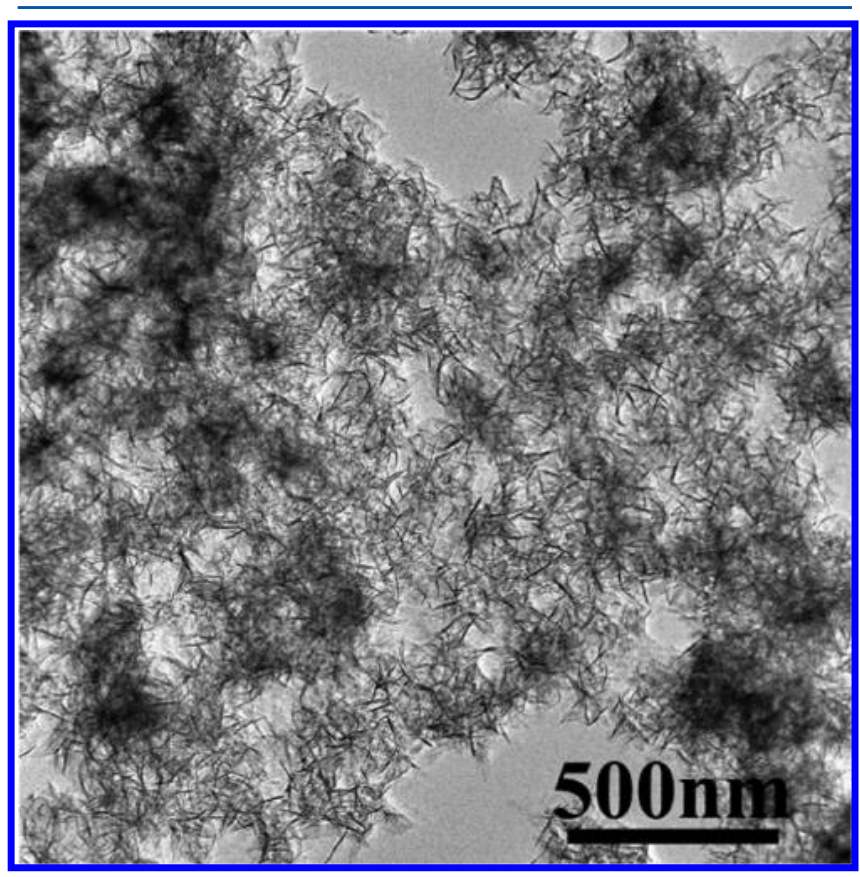

Figure 1. TEM overview of the as-synthesized $\mathrm{SnO}_{2} \mathrm{NSs}$ (sample SA3, $t=6 \mathrm{~h}, c=15.8 \mathrm{mM}, r=50 \%$ with $0.8 \mathrm{M} \mathrm{NH}_{3} \cdot \mathrm{H}_{2} \mathrm{O}$ at $120{ }^{\circ} \mathrm{C}$ with rapid cooling).

prepared $\mathrm{SnO}_{2}$ NSs $(t=6 \mathrm{~h}, c=15.8 \mathrm{mM}, r=50 \%, 0.8 \mathrm{M}$ $\mathrm{NH}_{3} \cdot \mathrm{H}_{2} \mathrm{O}$ at $120{ }^{\circ} \mathrm{C}$ with rapid cooling, named as sample SA3). The sample features high purity in the form of well-defined NSs. The light regions suggest planar or bended thin sheets lying on the substrate, with edge lengths most likely less than
$100 \mathrm{~nm}$ in lateral dimensions and thicknesses of about $5 \mathrm{~nm}$. Relatively dark regions indicate that some sheets may either lie aslant, perpendicularly to the substrate or spontaneously convolute due to minimization of surface energy. This sample is also investigated by SEM, which further confirms its high morphological purity (see Supporting Information, Figure S2). To obtain thermal stability, these $\mathrm{SnO}_{2}$ NSs gradually grow into 3-D self-organized architecture, as demonstrated for ultrathin $\mathrm{TiO}_{2}$ and zeolite NSs. ${ }^{54,55}$

Figure 2 shows the indexed XRD patterns of samples obtained from various reaction times $(4,5$, and $6 \mathrm{~h}$, named as

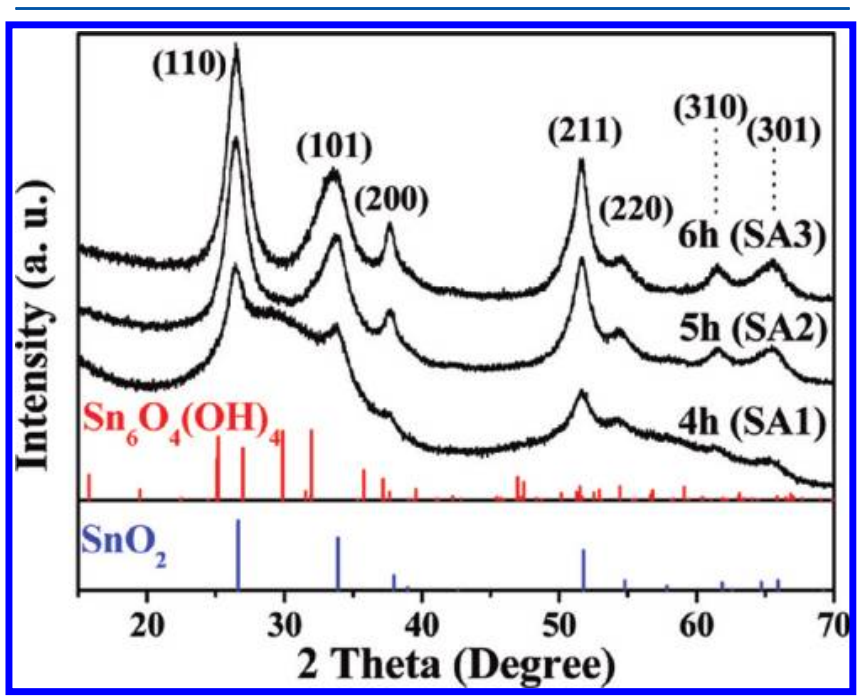

Figure 2. XRD patterns of the products synthesized by $4 \mathrm{~h}$ (SA1), $5 \mathrm{~h}$ (SA2), and $6 \mathrm{~h}$ (SA3) while keeping other parameters constant $(c=$ $15.8 \mathrm{mM}, r=50 \%, 0.8 \mathrm{M} \mathrm{NH}_{3} \cdot \mathrm{H}_{2} \mathrm{O}$ at $120^{\circ} \mathrm{C}$ with rapid cooling). Standard peak positions and intensities are accordingly marked for $\mathrm{Sn}_{6} \mathrm{O}_{4}(\mathrm{OH})_{4}$ (JCPDS No. 46-1486) and $\mathrm{SnO}_{2}$ (JCPDS No. 41-1445).

sample SA1, SA2, and SA3, respectively) while keeping the other conditions identical $(c=15.8 \mathrm{mM}, r=50 \%, 0.8 \mathrm{M}$ $\mathrm{NH}_{3} \cdot \mathrm{H}_{2} \mathrm{O}$ at $120{ }^{\circ} \mathrm{C}$ with rapid cooling). It can be seen that as the reaction time increases, the diffraction peaks of $\mathrm{Sn}_{6} \mathrm{O}_{4}(\mathrm{OH})_{4}$ gradually vanish while the peak intensities of rutile $\mathrm{SnO}_{2}$ (cassiterite, JCPDS card No. 41-1445, space group: $\left.P 4_{2} / m n m, a=4.7380 \AA, c=3.1865 \AA\right)$ keep increasing. In this sense, $\mathrm{Sn}(\mathrm{II})_{6} \mathrm{O}_{4}(\mathrm{OH})_{4}$ should experience a gradual decomposition into highly pure $\mathrm{Sn}(\mathrm{IV}) \mathrm{O}_{2}$ after $6 \mathrm{~h}$ hydrothermal reaction. No other peaks are found in the XRD pattern of sample SA3. It appears that the (110) and (101) peaks are relatively broader than the other peaks, which might be linked with the possibly strained common attachment planes of $\{110\}$ and $\{101\}$ in the $\mathrm{SnO}_{2}$ NSs structure. Earlier assumptions of compressive stress ${ }^{56-58}$ must be disregarded as the stress/strain parameter obtained through Williamson-Hall plots is a rootmean-square (rms) value and cannot distinguish between compressive and tensile stress. ${ }^{59-61}$ Rietveld refinements employing Voigt function profiles on the XRD data fits well with nanometer-sized $\mathrm{SnO}_{2} \mathrm{NSs}$ of on average 2-3 nm thicknesses in the $a$ or $b$ direction and about $10 \mathrm{~nm}$ along the others (see Supporting Information, Figure S3).

Figure $3 \mathrm{a}-\mathrm{d}$ shows representative TEM images of both $\mathrm{Sn}_{6} \mathrm{O}_{4}(\mathrm{OH})_{4}$ intermediate and three products studied in Figure 2a (samples SA1, SA2, and SA3). From these pictures, one can clearly see an evolution from poorly crystallized intermediate to final nanosheet-based hierarchical architectures. The morpho- 


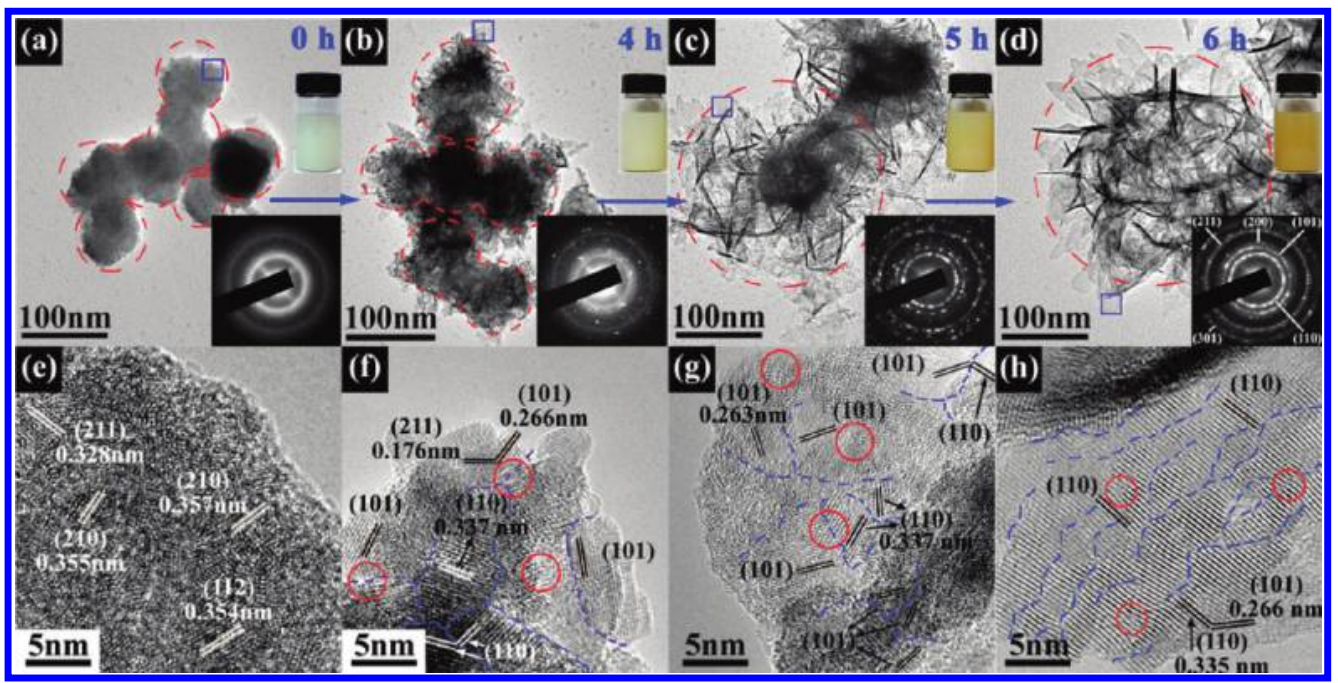

Figure 3. $(\mathrm{a}-\mathrm{d})$ Typical TEM images and corresponding SAED patterns (bottom right corner insets) of $\mathrm{Sn}_{6} \mathrm{O}_{4}(\mathrm{OH})_{4}, 4 \mathrm{~h}(\mathrm{SA} 1), 5 \mathrm{~h}(\mathrm{SA} 2)$ and $6 \mathrm{~h}$ (SA3) $\mathrm{SnO}_{2}$ samples $\left(c=15.8 \mathrm{mM}, r=50 \%, 0.8 \mathrm{M} \mathrm{NH}_{3} \cdot \mathrm{H}_{2} \mathrm{O}\right.$ at $120{ }^{\circ} \mathrm{C}$ with rapid cooling). The upper right corner inset in each TEM image discloses the color variation of each sample. (e-h) HRTEM images of the aforementioned four samples drawn from the area denoted by blue squares in $(\mathrm{a}-\mathrm{d})$. The dashed blue lines correspond to the obvious crystal interfaces in $\mathrm{SnO}_{2}$ nanostructures. From these pictures, it can be clearly seen that $\mathrm{Sn}_{6} \mathrm{O}_{4}(\mathrm{OH})_{4}$ transformed to randomly oriented $\mathrm{SnO}_{2} \mathrm{NPs}$, which further grow into $\mathrm{SnO}_{2} \mathrm{NSs}$ through oriented attachment mode.

logical transition occurs initially at the fringes of each "cluster" (denoted by red circles) and gradually moves to the inner spaces until well-defined nanosheets completely form in sacrifice of all the interconnected NPs. Meanwhile, all the socalled "clusters" experience a large volume expansion and attain better crystallinity when going from $\mathrm{Sn}_{6} \mathrm{O}_{4}(\mathrm{OH})_{4}$ to $\mathrm{SnO}_{2}$, as corroborated in their corresponding selected-area electron diffraction (SAED) patterns (lower right insets). In addition, the SAED pattern of sample SA3 (inset of Figure 3d) can be well indexed as (110), (101), (200), (211), and (301) planes of rutile $\mathrm{SnO}_{2}$ (JCPDS card No. 41-1445), which is in good agreement with the above XRD result. The upper right inset in each TEM picture discloses the color variation of the above four products, from yellow-white $\left(\mathrm{Sn}_{6} \mathrm{O}_{4}(\mathrm{OH})_{4}\right)$ to yellow (sample SA1) and then dark yellow (sample SA3). Usually, the intrinsic $\mathrm{SnO}_{2}$ nanocrystal is white due to reflection of visible light, which results from its wide band gap of $3.6 \mathrm{eV}$. In this case, the aforementioned color variation trend may be mainly attributed to "F-centers" brought by a potential increase in oxygen vacancies in the samples, which will be discussed in the following sections.

Oriented Attachment Mechanism of $\mathrm{SnO}_{2}$ NSs. In order to deeper understand the evolution processes and elucidate the growth mechanism of $\mathrm{SnO}_{2}$ NSs, we also performed HRTEM on a random site in each TEM image (Figure $3 \mathrm{e}-\mathrm{h}$ ). In Figure $3 \mathrm{e}$, the lattices can be related to (210), (112), and (211) planes of $\mathrm{Sn}_{6} \mathrm{O}_{4}(\mathrm{OH})_{4}$ crystal (JCPDS card No. 46-1486). Besides these short-range ordered lattices, arbitrary aligned atom projections in other sites reveal its partially amorphous character. This finding agrees with its XRD result. After $4 \mathrm{~h}$ hydrothermal treatment, the edges of the "clusters" start to render $\mathrm{SnO}_{2}$ rutile structured NPs with lattices of (110), (101), and (211) planes. However, these particles are randomly oriented, and no sheetlike morphologies are observed. As the reaction time is prolonged to $5 \mathrm{~h}$, similar orientation of $\mathrm{SnO}_{2}$ (101) planes were clearly detected in four areas (denoted by red circles), and the homogenously shallow contrast across these areas indicates the emergence of 2dimensional sheets. After $6 \mathrm{~h}$, the lattice fringes in Figure $3 \mathrm{~h}$ feature highly oriented $\mathrm{SnO}_{2}$ NSs along the [110] direction. Many crystal interfaces and dislocations are observed in the nanosheet. This fact indicates that $\mathrm{SnO}_{2} \mathrm{NSs}$ prepared here may be comprised of a number of oriented nanocrystals which fuse into one integrated sheet.

Combining XRD and TEM with HRTEM results, we suggest that the evolution process to $\mathrm{SnO}_{2} \mathrm{NSs}$ is through oriented attachment growth fashion. This process is a complex chain reaction, which probably starts by the coalescences of randomly oriented $\mathrm{SnO}_{2}$ NPs obtained from decomposition of $\mathrm{Sn}_{6} \mathrm{O}_{4}(\mathrm{OH})_{4}$ and is followed by consecutive rotations in 3dimensional spaces as well as drastic interfacial relaxations so as to achieve full fusion. A similar phenomenon was already detected by in situ HRTEM observation in the $\mathrm{SnO}_{2} / \mathrm{TiO}_{2}$ or PbSe systems. ${ }^{62,63}$

To better verify the above assumptions, the $\mathrm{SnO}_{2} \mathrm{NSs}$ samples prepared by $24 \mathrm{~h}$ (Figure 4a,c, sample SA4) and $48 \mathrm{~h}$ (Figure $4 \mathrm{~b}$,d, sample SA5) are also characterized by TEM and HRTEM, respectively. Clearly, the ultrathin NSs in these two samples grow planar than those obtained by $6 \mathrm{~h}$ reaction. SAED patterns disclose that the products are mainly rutile $\mathrm{SnO}_{2}$ (JCPDS card No. 41-1445). Figure 4c displays a HRTEM image drawn from Figure 4a; the interplanar distances in the picture are $0.374,0.334$, and $0.282 \mathrm{~nm}$. Two fast Fourier transforms (FFT) of local area are given in the upper corner. Similarly, Figure 4d presents a HRTEM image drawn from Figure $4 \mathrm{~b}$. The long-range ordered lattice (with a slight mistilt of $\varphi=2^{\circ}$ ) implies that the integrated planar NS is formed after $48 \mathrm{~h}$ reaction; namely, full fusion of large numbers of nanocrystals has almost been accomplished. The interplanar distances are measured to be $0.348,0.335$, and $0.282 \mathrm{~nm}$. Surprisingly, these interplanar distances are consistent to a possible $\mathrm{Sn}_{3} \mathrm{O}_{4}$ structure proposed by White et al. ${ }^{64}$ (monoclinic, space group: $P 2_{1} / c, a=8.2100 \AA, b=4.9300 \AA$, $c=5.8500 \AA, \beta=94.7^{\circ}$ ) rather than rutile $\mathrm{SnO}_{2}$. In fact, we further employ XRD to ascertain the inherent structure of the products prepared by $48 \mathrm{~h}$. The XRD pattern reveals that most of the products still existed as $\mathrm{SnO}_{2}$ while trivial $\mathrm{Sn}_{3} \mathrm{O}_{4}$ were found through asymmetric left shoulder of $\mathrm{SnO}_{2}$ (101) peak 


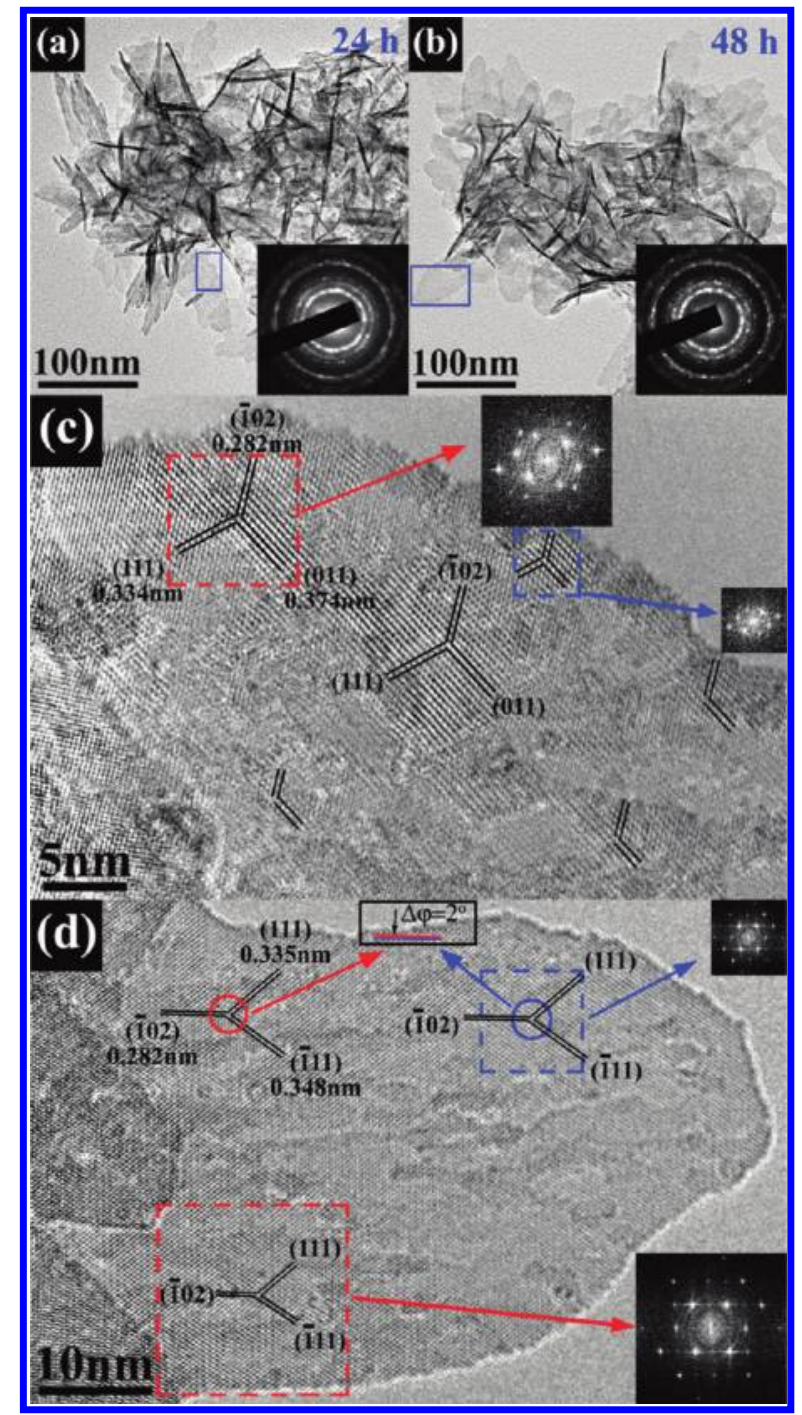

Figure 4. TEM images of $\mathrm{SnO}_{2}$ prepared by (a) $24 \mathrm{~h}$ (SA4) and (b) $48 \mathrm{~h}$ (SA5) without changing other parameters $(c=15.8 \mathrm{mM}, r=50 \%$, $0.8 \mathrm{M} \mathrm{NH}_{3} \cdot \mathrm{H}_{2} \mathrm{O}$ at $120{ }^{\circ} \mathrm{C}$ with rapid cooling). (c, d) HRTEM images taken from (a) and (b), respectively. The atom projection alignments reveal a possible structure of $\mathrm{Sn}_{3} \mathrm{O}_{4}$ instead of $\mathrm{SnO}_{2}$.

(see Supporting Information, Figure S4). The origin of $\mathrm{Sn}_{3} \mathrm{O}_{4}$ will be discussed later.

Inherent Nonstoichiometry in $\mathrm{SnO}_{2}$ NSs. The chemical composition of the as-synthesized $\mathrm{SnO}_{2} \mathrm{NSs}$ (sample SA3) was carefully investigated by X-ray photoelectron spectroscopy (XPS) analysis, as shown in Figure 5. From the full spectrum (Figure 5a), only Sn, O, and $\mathrm{C}$ elements are observed, and no other impurity peaks exist, which again confirm the purity of $\mathrm{SnO}_{2}$ NSs. The binding energy of $\mathrm{C} 1 \mathrm{~s}$ peak at $284.8 \mathrm{eV}$ is used as the reference point for charge correcting. Figure $5 \mathrm{~b}$ displays the high-resolution $\mathrm{O} 1 \mathrm{~s}$ spectrum of this sample. According to the literature, ${ }^{65-67}$ the lower binding energy (centered at 531.1 $\mathrm{eV}$ ) is attributed to the coordination of oxygen bounded to tin atoms, whereas the higher binding energy component (centered at $532.9 \mathrm{eV}$ ) develops due to the loss of oxygen, giving rise to nonstoichiometric defects in $\mathrm{SnO}_{2} \mathrm{NSs}$. The highresolution $S n 3 d$ spectra are shown in Figure $5 c$. Both $S n 3 d_{5 / 2}$ and $S n 3 d_{3 / 2}$ peaks are found to be asymmetric. It has been confirmed by both HRTEM observations and theoretical calculations that the nonstoichiometric oxygen deficiency

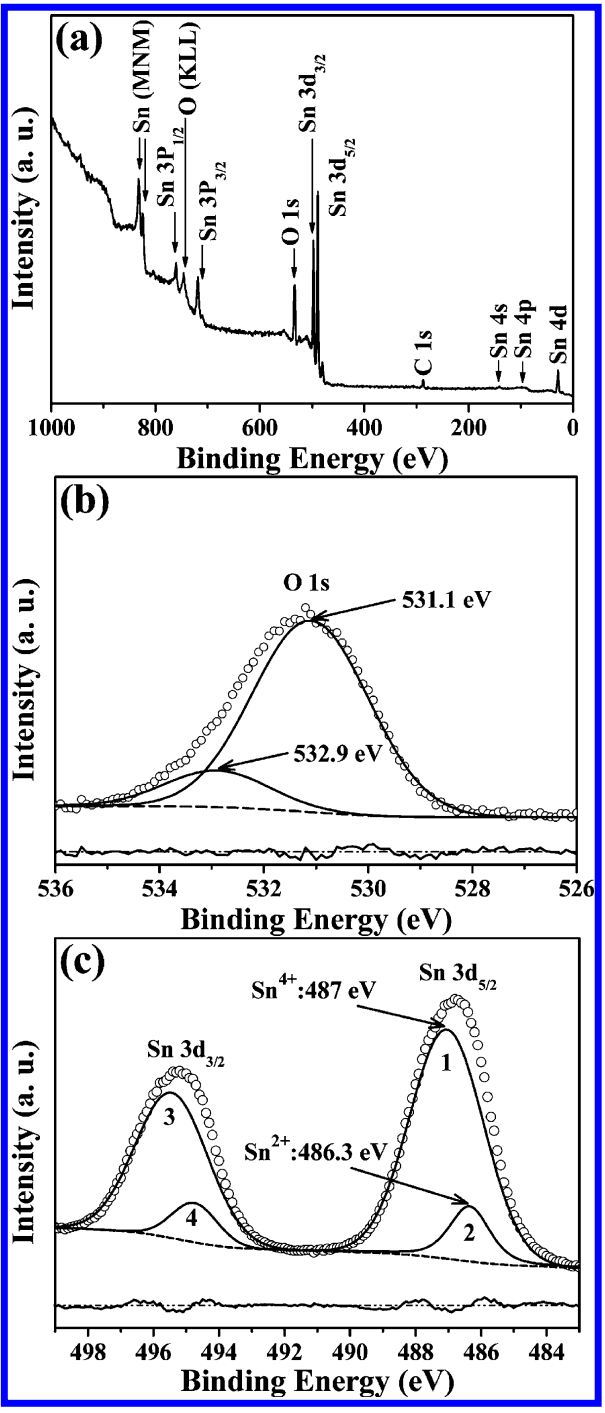

Figure 5. (a) XPS full spectrum of well-defined $\mathrm{SnO}_{2}$ NSs sample (SA3). (b) Deconvoluted $\mathrm{O} 1 \mathrm{~s}$ peak for the $\mathrm{SnO}_{2}$ NSs. (c) Deconvoluted Sn 3d spectra showing the existence of $\mathrm{Sn}^{2+}$ in the final product. Shirley backgrounds (broken lines below fits) were chosen for each of the elements to produce random residuals (shown in the bottom of (b) and (c)).

$\left(\mathrm{SnO}_{2-x}\right)$ induced by oxygen vacancies $\left(\mathrm{V}_{\mathrm{o}}\right)$ inevitably results in charge compensation via $\mathrm{Sn}^{4+}$ ions reducing to $\mathrm{Sn}^{2+}$ rather than $\mathrm{Sn}^{3+}{ }^{68-70}$ The chemical shift of $\sim 0.7 \mathrm{eV}$ between $\mathrm{Sn}^{4+}$ and $\mathrm{Sn}^{2+}$ is accordingly reported from previous studies. ${ }^{71,72} \mathrm{On}$ this basis, each Sn 3d peak could be respectively deconvoluted into two peaks (numbered 1, 2, 3, and 4). Peak 1 (centered at $487 \mathrm{eV}$ ) and peak 3 (centered at $495.4 \mathrm{eV}$ ) correspond to $\mathrm{Sn}^{4+}$ bound to oxygen in $\mathrm{SnO}_{2}$. The spin-orbit splitting of $8.4 \mathrm{eV}$ is consistent with that previously reported. ${ }^{73-75}$ Peak 2 (centered at $486.3 \mathrm{eV}$ ) and peak 4 (centered at $494.7 \mathrm{eV}$ ) are ascribed to $\mathrm{Sn}^{2+}$ in the matrix. The best fit to $\mathrm{Sn} 3 \mathrm{~d}_{5 / 2}$ level in Figure $5 \mathrm{c}$ presents an area ratio $A\left(\mathrm{Sn}^{2+}\right) /\left[A\left(\mathrm{Sn}^{2+}\right)+A\left(\mathrm{Sn}^{4+}\right)\right]=0.13$, suggesting that about $13 \%$ of $\mathrm{Sn}$ ions in $\mathrm{SnO}_{2}$ NSs have been reduced to divalent $\mathrm{Sn}^{2+}$ ions which probably existed as $\mathrm{Sn}_{3} \mathrm{O}_{4}$.

In order to elucidate the ultrathin thicknesses of $\mathrm{SnO}_{2} \mathrm{NSs}$, a diluted suspension (sample SA3) was ultrasonicated and dropcast onto cleaned silicon wafer and analyzed through atomic force microscopy (AFM). Figure 6 shows the AFM image of this sample and a height profile is taken along a black line. The 


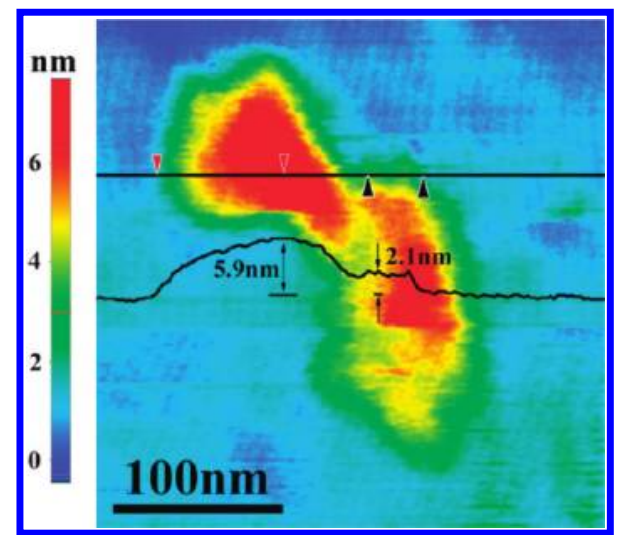

Figure 6. Tapping mode AFM image of $\mathrm{SnO}_{2} \mathrm{NSs}$ (SA3) with a height profile (black curve) taken along a black line. The black markers correspond to an edge thickness of $\sim 2.1 \mathrm{~nm}$, whereas the red markers most probably correspond to two stacked NSs.

black markers on the right of black line indicate an edge of a single NS, and the thickness is determined to be $\sim 2.1 \mathrm{~nm}$. The red markers on the left of this black line show a height difference of $\sim 5.9 \mathrm{~nm}$; this value is most probably caused by two stacked and/or curled nanosheets. By means of HRTEM image simulation, ${ }^{49}$ we found that the thicknesses of $\mathrm{SnO}_{2} \mathrm{NSs}$ were about $1.5-3.0 \mathrm{~nm}$ on the edge. This expectation is in good agreement with our finding here. To better verify this conclusion, we also carefully investigated some well-defined $\mathrm{SnO}_{2}$ NSs (SA3) which were perpendicular to the substrate in HRTEM (see Supporting Information, Figure S5). The representative cross-section observations revealed the measured thicknesses of some randomly chosen NSs were 2.16, 2.18, and $3.60 \mathrm{~nm}$. These results are also in good accordance with AFM height profile and previous HRTEM image simulations.

Figure $7 \mathrm{a}$ shows the UV-vis absorption curve of the assynthesized $\mathrm{SnO}_{2}$ NSs (sample SA3) recorded from 610 to 220 $\mathrm{nm}$. Interestingly, our result is quite different with previous reports. ${ }^{58,76,77}$ In those works, the absorption partition did not start until $\sim 340 \mathrm{~nm}$; this phenomenon was related with an intrinsically optical transition generating an electron in the conduction band and a hole in the valence band. Whereas in our study, two absorption shoulders (480-320 nm denoted by blue rectangle and $290-250 \mathrm{~nm}$ denoted by red rectangle) distinctly exist in the overall spectrum. The high-energy absorption onset of $\sim 290 \mathrm{~nm}$ is owing to the electron transition from valence to conduction band, and the visible light absorption from 480 to $320 \mathrm{~nm}$ is probably attributed to oxygen vacancies $\left(\mathrm{V}_{\mathrm{o}}\right)$ induced impurity energy states in between the band gap. Moreover, the increasing absorption starting from $480 \mathrm{~nm}$ (blue-green light) rendered the $\mathrm{SnO}_{2}$ sample (SA3) exteriorly yellow, quite in accordance with experimental photograph shown in the inset of Figure $3 \mathrm{~d}$. To determine the optical band gap energy $E_{\mathrm{g}}$ for this $\mathrm{SnO}_{2} \mathrm{NSs}$ sample, the following equation is used: ${ }^{56,78}$

$$
(\alpha h \nu)^{n}=A\left(h \nu-E_{\mathrm{g}}\right)
$$

where $\alpha$ is the absorption coefficient, $h$ is Planck's constant, $\nu$ is the radiation frequency, $A$ is the parameter that relates to the effective masses associated with the valence band and conduction band, $E_{\mathrm{g}}$ is the band gap energy, and the value of $n$ is 2 for direct band gap semiconductors and $1 / 2$ for indirect band gap semiconductors. In this case, $n$ is 2 for $\mathrm{SnO}_{2}$ and $\alpha$ is

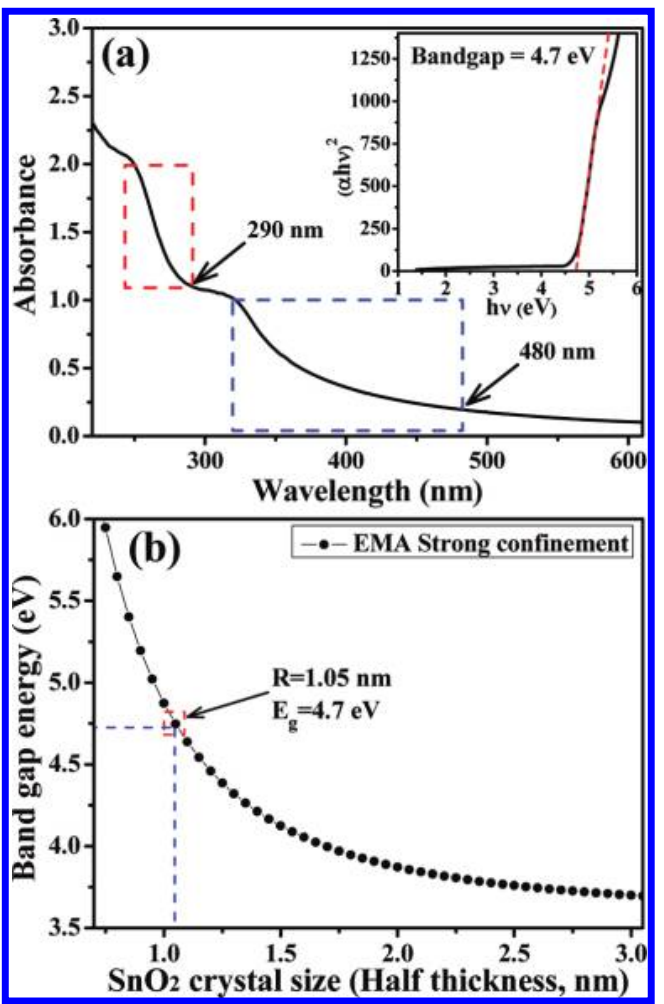

Figure 7. (a) UV-vis absorption spectrum of the as-synthesized $\mathrm{SnO}_{2}$ NSs sample (SA3) and corresponding plot of $(\alpha h \nu)^{2}$ vs photon energy (upper right inset), which exhibits a band gap energy of about $4.7 \mathrm{eV}$ for this sample. (b) Calculated size (mean half-thickness of $\mathrm{SnO}_{2}$ NSs)-bandgap results using EMA strong-confinement models.

obtained from UV-vis diffuse reflectance curve using the Kubelka-Munk function: ${ }^{79}$

$$
F(R)=\frac{\alpha}{S}=\frac{(1-R)^{2}}{2 R}
$$

where $R$ is the corresponding reflectance intensity at the same energy point $(h \nu)$ of the above equation and $S$ is the scattering coefficient. Using these parameters, a curve of $(\alpha h \nu)^{2}$ vs $h \nu$ is plotted in the inset of Figure $7 \mathrm{a}$, and the optical band gap energy of $\mathrm{SnO}_{2} \mathrm{NSs}$ is estimated to be $4.7 \mathrm{eV}$ from the extrapolated intercept of the linear portion to the plot. This value of band gap is much larger than that for bulk $\mathrm{SnO}_{2}(3.6$ $\mathrm{eV})$. For semiconductor nanomaterials, the quantum confinement effect is readily expected to subject to decreasing particle sizes. When the crystal sizes of nanostructures are smaller than its exciton Bohr radius, the effective band gap energy of $E_{\mathrm{g}}^{\mathrm{eff}}$ is calculated by eq 3 using the effective mass approximation (EMA): ${ }^{80,81}$

$$
E_{\mathrm{g}}^{\mathrm{eff}}=E_{\mathrm{g}}+\frac{\hbar^{2} \pi^{2}}{2 \mu R^{2}}-\frac{1.8 e^{2}}{4 \pi \varepsilon \varepsilon_{0} R}+\ldots
$$

where $E_{\mathrm{g}}$ is the bulk band gap energy, $\hbar$ is Planck's constant divided by $2 \pi, \mu$ is the effective reduced mass $\left(\mu \approx m_{\mathrm{e}}{ }^{*}=\right.$ $\left.0.275 m_{\mathrm{e}}\right), R$ is the nanocrystal radius, $\varepsilon_{0}$ is the static dielectric constant, and $\varepsilon=14$ for $\mathrm{SnO}_{2} .{ }^{82}$ In combination with aforementioned XRD, HRTEM, and AFM observations, nearly all the $\mathrm{SnO}_{2} \mathrm{NSs}$ exhibit lateral length from 30 to $80 \mathrm{~nm}$ and thicknesses in the regime of ca. 2.1-3.6 nm (i.e., the halfthicknesses are 1.05-1.8 nm, less than the exciton Bohr radius of $\left.2.7 \mathrm{~nm}^{83,84}\right)$. Therefore, the as-synthesized $\mathrm{SnO}_{2} \mathrm{NSs}$ in the 
thickness direction are in a rather strong quantum confinement regime, while in the lateral dimensions, the electrons are highly delocalized, leading to negligible confinement effect. By employing eq 3, a plot of $E_{\mathrm{g}}^{\text {eff }}$ over the half thickness is drawn (Figure $7 \mathrm{~b}$ ). From this plot, the enlarged band gap energy of $4.7 \mathrm{eV}$ corresponds to the mean half-thickness of $\sim 1.05 \mathrm{~nm}$, namely, $\sim 2.1 \mathrm{~nm}$ average thickness for $\mathrm{SnO}_{2}$ NSs, which in return remarkably well coincides with the minimum thickness observed in AFM and HRTEM cross-section images. In addition, minor $\mathrm{Sn}_{3} \mathrm{O}_{4}$ existing in the sample inevitably contributes to the band gap energy. However, it seems that the ultrathin thickness-dependent quantum confinement dominates this band gap widening.

Synthetic Effect of Specific $r$ Values. It is known that structures and morphologies of the as-prepared materials are significantly affected by different reaction conditions. Here we systematically discuss these relationships as follows. Since the $r$ value $\left(\mathrm{EtOH}\right.$ vol \% in the mixture of EtOH$-\mathrm{H}_{2} \mathrm{O}$ ) is closely related to the polarity of solvent, we first study this synthetic effect brought by specific $r$ value of $0 \%$ (SA6), 25\% (SA7), 75\% (SA8), and $100 \%$ (SA9) (Figure 8). When $r=0 \%$, i.e. the

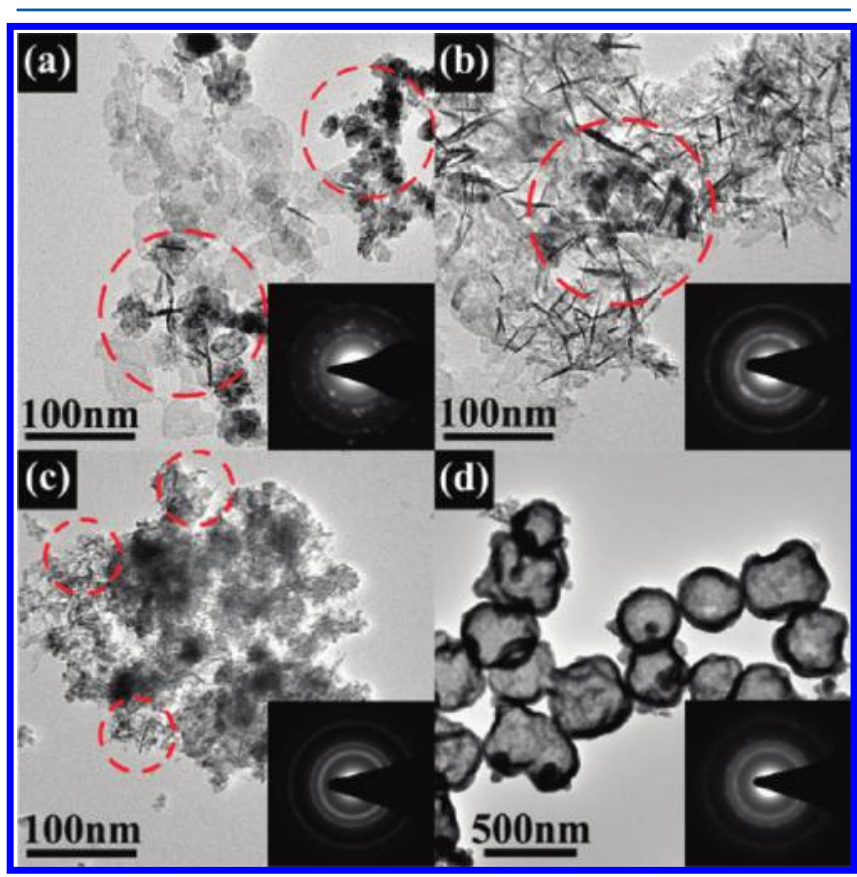

Figure 8. TEM images of $\mathrm{SnO}_{2}$ products by changing $r$ values (a) $0 \%$ (SA6), (b) 25\% (SA7), (c) 75\% (SA8), and (d) 100\% (SA9) while keeping other synthetic parameter identical $(t=6 \mathrm{~h}, c=15.8 \mathrm{mM}, 0.8$ $\mathrm{M} \mathrm{NH}_{3} \cdot \mathrm{H}_{2} \mathrm{O}$ at $120{ }^{\circ} \mathrm{C}$ with rapid cooling). The lower right inset in each image reveals $\mathrm{SnO}_{2}$ rutile structure (JCPDS card No. 41-1445).

solvent is pure water, 3-D hierarchical morphologies could hardly form; instead, most of the products exhibit either planar flakes or irregular aggregated particles (denoted by red circles). As the polarity decreases $(r=25 \%)$, the products consist of a mixture of $\mathrm{SnO}_{2}$ NSs and a few irregular NPs (denoted by red circles). $\mathrm{SnO}_{2}$ NSs are predominant at this configuration but not so well-defined as compared to those with $r=50 \%$ (SA3). Unpredictably, the final products turn out as a large amount of small particles after the $r$ value increases to $75 \%$, with trivial small-sized NSs (denoted by red circles). In addition, if the solvent is exclusively ethanol $(r=100 \%)$, the products tend to be ill-defined hollow spheres, the diameter of which are in the regime of $300 \mathrm{~nm}$. Regardless of the imperfect spherical appearances, this method offers another facile route to obtain hollow spheres which are always under the spotlight in the field of lithium-ion batteries (LIB). ${ }^{85-87}$

Effect of Additives. Besides the $r$ value, the effect of additives is also evaluated. Figure S6a (see Supporting Information) presents a HRTEM capture of the product obtained without adding $\mathrm{NH}_{3} \cdot \mathrm{H}_{2} \mathrm{O}$. Interconnected $\mathrm{SnO}_{2} \mathrm{NPs}$ are deduced from hydrothermal treatment of the simple mixture of $\mathrm{SnCl}_{2}, \mathrm{EtOH}$, and $\mathrm{H}_{2} \mathrm{O}$. The $\mathrm{SnO}_{2}$ rutile structure is revealed by its interplanar distance of $0.335 \mathrm{~nm}(\{110\}$ planes). It is also found that the product yield is much lower than that for the $\mathrm{SnO}_{2}$ NSs sample. This is probably due to decreased generation of $\mathrm{Sn}_{6} \mathrm{O}_{4}(\mathrm{OH})_{4}$ without adding $\mathrm{NH}_{3} \cdot \mathrm{H}_{2} \mathrm{O}$. Figure S6b (see Supporting Information) shows a typical TEM image of the products obtained by adding $0.8 \mathrm{M}$ urea as additive instead of $\mathrm{NH}_{3} \cdot \mathrm{H}_{2} \mathrm{O}$. From this picture, most of the products are NPs, while only a few ill-defined NSs are produced. The SAED pattern confirms $\mathrm{SnO}_{2} \mathrm{NPs}$ with a rutile structure. It is thought that the $-\mathrm{OH}$ group of ethanol, $-\mathrm{NH}_{2}$ group of urea, and $\mathrm{NH}_{4}{ }^{+}$of aqueous ammonia play important roles as surface-modifying reagent in the reactions. ${ }^{88-95}$ Because of their different ability to bind to $\mathrm{Sn}$ ions or form hydrogen bonds, these functional groups may lead to the variation in surface energy of $\mathrm{SnO}_{2}$ nanocrystals. Under certain conditions, the spontaneous elimination of high-energy surfaces renders the $\mathrm{SnO}_{2} \mathrm{NPs}$ aggregate in a planar way (as in sample $\mathrm{SA} 3$ ), responsible for the formation of $\mathrm{SnO}_{2}$ NSs.

Effect of Precursor Concentrations. Apart from the aforementioned synthetic parameters, the effect of precursor concentration was then investigated $(t=6 \mathrm{~h}, r=50 \%, 0.8 \mathrm{M}$ $\mathrm{NH}_{3} \cdot \mathrm{H}_{2} \mathrm{O}$ at $120{ }^{\circ} \mathrm{C}$ with rapid cooling) (see Supporting Information, Figure S7). As the precursor concentration was reduced from $15.8 \mathrm{mM}$ (SA3) to $6.8 \mathrm{mM}$ (SA10), most of the $\mathrm{SnO}_{2}$ existed as crumpled or rippled sheets lying on the substrates. When the concentration increased up to $31.6 \mathrm{mM}$ (SA11), 3-D configuration existed, similar to well-defined $\mathrm{SnO}_{2}$ NSs sample (SA3). However, it was found that some other amorphous-like spherical clusters also existed. By employing $\mathrm{XRD}$ measurements, the product indicated a mixture of both $\mathrm{SnO}_{2}$ and $\mathrm{Sn}_{6} \mathrm{O}_{4}(\mathrm{OH})_{4}$ (see Supporting Information, Figure S8). This means that under high precursor concentration no excess oxygen can be supplied to consume all $\mathrm{Sn}_{6} \mathrm{O}_{4}(\mathrm{OH})_{4}$ intermediate. In this case, the precursor concentration is another strict parameter in controlling the morphologies of the final product, and only modest concentration (i.e., $15.8 \mathrm{mM}$ ) resulted in pure and well-organized $\mathrm{SnO}_{2} \mathrm{NSs}$.

Effect of Cooling Rate. During our experiments, we found that natural cooling instead of fast cooling of autoclave or prolonged reaction time ( 24 or $48 \mathrm{~h}$ ) gave rise to some black byproducts besides $\mathrm{SnO}_{2}$ NSs (see Supporting Information, Figure S9) which were subsequently confirmed to be $\mathrm{SnO}$ by XRD (see Supporting Information, Figure S10). From the XRD results, (002) is distinctly the preferential plane, whereas (101) and (110) peaks are rather weak compared to its standard intensities. In our previous work, ${ }^{96}$ the surface energies of $\mathrm{SnO}$ were calculated by first-principles total energy calculations based on density functional theory (DFT) using the Vienna Abinitio Simulation Package (VASP) code. ${ }^{97}$ In the order of increasing energy, the surfaces form a sequence of $\{001\}<$ $\{110\}<\{112\}<\{111\}<\{101\}$. This calculation result is generally consistent to our XRD information. These precipitates are further examined by SEM and found to be mostly 
single plates or crossed plates. The edge lengths of these plates range from 5 to $20 \mu \mathrm{m}$. Figure 9a shows a typical low-

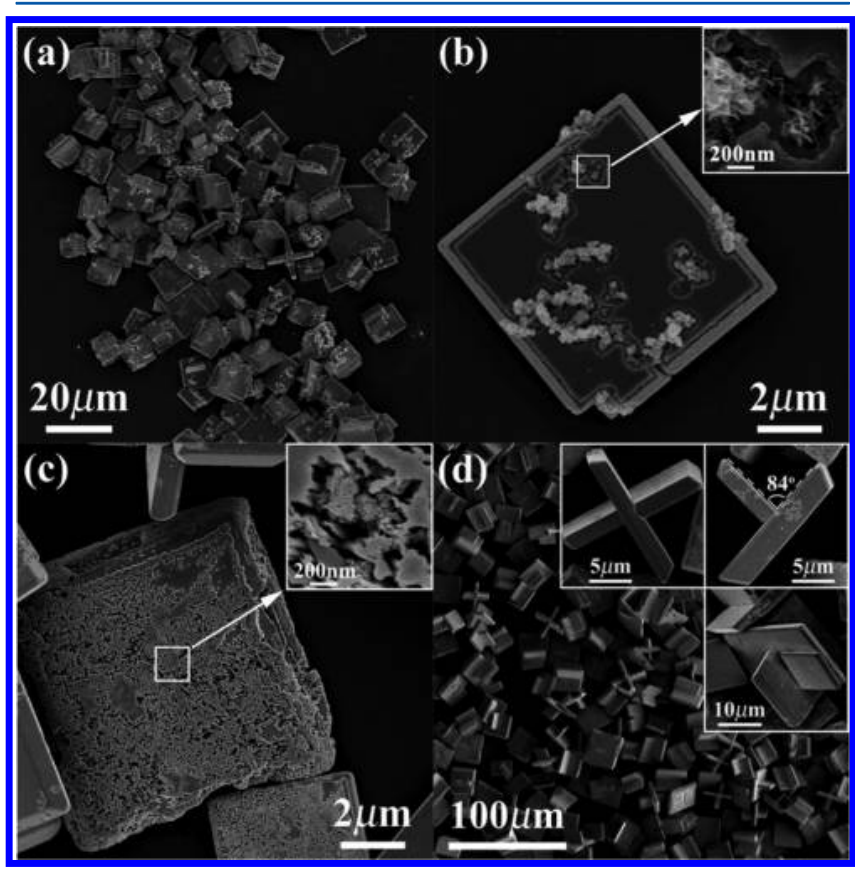

Figure 9. (a) SEM images of $\mathrm{SnO}$ byproducts synthesized by natural cooling of sample SA3. $(t=6 \mathrm{~h}, c=15.8 \mathrm{mM}, r=50 \%, 0.8 \mathrm{M}$ $\mathrm{NH}_{3} \cdot \mathrm{H}_{2} \mathrm{O}$ at $120{ }^{\circ} \mathrm{C}$ ). (b, c) Magnified SEM images of SnO product shown in (a); the insets in each picture present untransformed NSs structures. (d) SEM images of SnO byproducts synthesized by natural cooling of sample SA7 $(t=6 \mathrm{~h}, c=15.8 \mathrm{mM}, r=25 \%, 0.8 \mathrm{M}$ $\mathrm{NH}_{3} \cdot \mathrm{H}_{2} \mathrm{O}$ at $120{ }^{\circ} \mathrm{C}$ ); the insets show various morphologies of $\mathrm{SnO}$.

magnification view of $\mathrm{SnO}$ products deduced from natural cooling to room temperature (SA3 configuration but with natural cooling: $t=6 \mathrm{~h}, c=15.8 \mathrm{mM}, r=50 \%, 0.8 \mathrm{M} \mathrm{NH}_{3} \cdot \mathrm{H}_{2} \mathrm{O}$ at $120{ }^{\circ} \mathrm{C}$ ). Closer looks at these poorly defined plates are shown in Figure 9b,c. In the untransformed areas (denoted by white pane), nanosheet-based hierarchical structures were clearly seen. It seemed that these NSs gradually dissolved and formed larger $\mathrm{SnO}$ crystals. In order to reach the $\mathrm{SnO}$ stoichiometry, $\mathrm{SnO}_{2}$ must inevitably be reduced. Interestingly, the $r$ value is also found to be closely related to the morphologies of $\mathrm{SnO}$. Figure 9d shows a typical lowmagnification view of $\mathrm{SnO}$ products deduced from natural cooling with SA7 configuration ( $t=6 \mathrm{~h}, c=15.8 \mathrm{mM}, r=25 \%$, $0.8 \mathrm{M} \mathrm{NH}_{3} \cdot \mathrm{H}_{2} \mathrm{O}$ at $120{ }^{\circ} \mathrm{C}$ ). It is obvious from this picture that most of the plates are more regular than those shown in Figure 10a, implying a more complete evolution. The upper right insets present three representative morphologies, including both symmetric and asymmetric type crosses. In addition, it should be stressed that $\mathrm{SnO}$ phase is more easily formed with the existence of $\mathrm{H}_{2} \mathrm{O}$. For instance, natural cooling of sample SA8 $(r=100 \%)$ rendered exclusively $\mathrm{SnO}_{2}$ (hollow spheres), whereas even rapid cooling of sample SA6 $(r=0 \%)$ would give a lot of $\mathrm{SnO}$ plates (see Supporting Information, Figure S11). After carefully inspecting the interplanar angle, it is found that the "twin model" based on formation mechanism proposed in ref 96 is also available in this case. Two crossed planes shared a common twin plane, i.e., the $\{112\}$ plane, and the angle of $84^{\circ}$ indicates that the two twined crystals planes are $\{001\}$ planes. Furthermore, rapid cooling of sample SA4 and SA5 also inevitably left quasi-evolved $\mathrm{SnO}$ plates. We believe that the

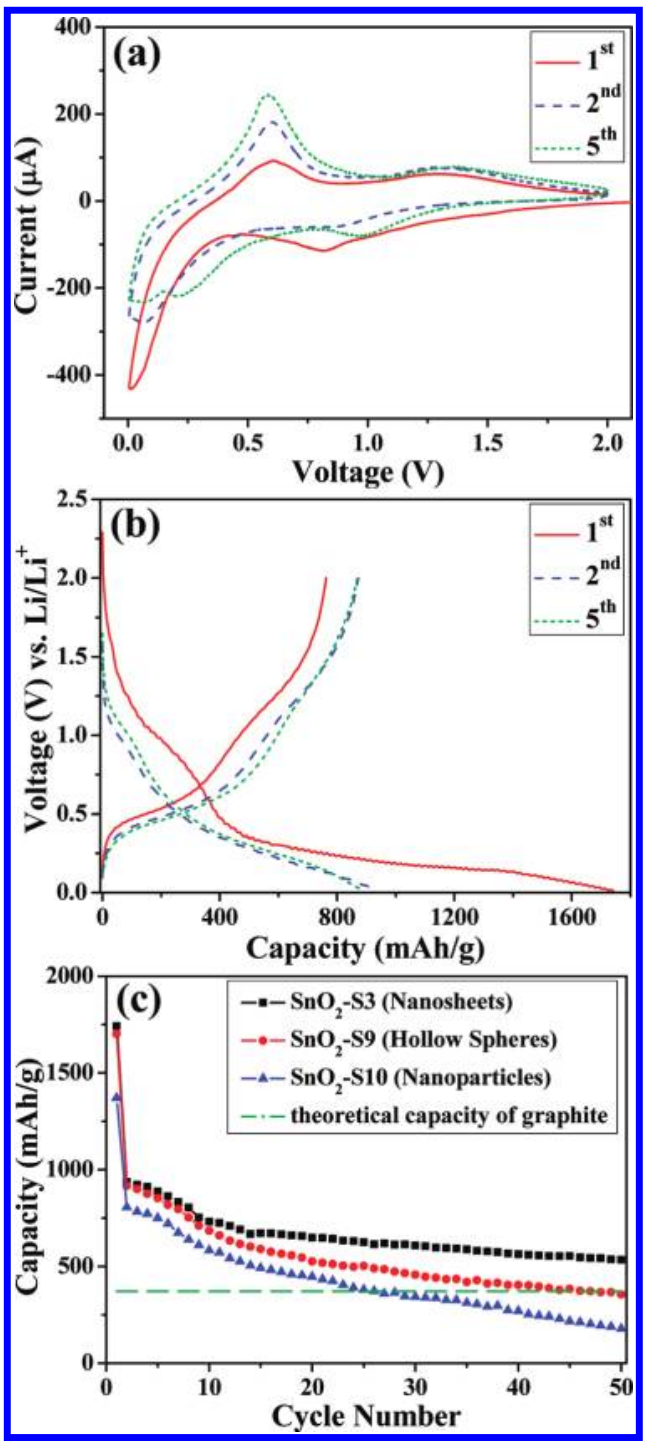

Figure 10. (a) Cyclic votammograms of $\mathrm{SnO}_{2} \mathrm{NSs}$ sample (SA3) at a scan rate of $0.1 \mathrm{mV} / \mathrm{s}$ between $2 \mathrm{~V}$ and $10 \mathrm{mV}$. (b) Charge-discharge voltage profiles of the $\mathrm{SnO}_{2}$ NSs (SA3) for the first, second, and fifth cycles at a current rate of $156 \mathrm{~mA} / \mathrm{g}$. (c) Cycling performance comparison of $\mathrm{SnO}_{2}$ NSs hollow spheres (SA9) and NPs (SA10) at a current density of $156 \mathrm{~mA} / \mathrm{g}$ with a voltage window of $2 \mathrm{~V}-10 \mathrm{mV}$.

whole phenomenon strongly related with thermodynamic equilibrium in the reaction system.

Overall Formation Mechanism of $\mathrm{SnO}_{2}$ Nanosheets. In combination with all the above sections, the product evolution is expressed by reactions $\mathrm{i}-\mathrm{iv}$ :

$$
\begin{aligned}
& 6 \mathrm{Sn}^{2+}+12 \mathrm{NH}_{3} \cdot \mathrm{H}_{2} \mathrm{O} \\
& \rightarrow \mathrm{Sn}_{6} \mathrm{O}_{4}(\mathrm{OH})_{4}+12 \mathrm{NH}_{4}{ }^{+}+4 \mathrm{H}_{2} \mathrm{O} \\
& \mathrm{Sn}_{6} \mathrm{O}_{4}(\mathrm{OH})_{4}+3 \mathrm{O}_{2} \rightarrow 6 \mathrm{SnO}_{2}+3 \mathrm{H}_{2} \mathrm{O} \\
& 3 \mathrm{SnO}_{2} \rightarrow \mathrm{Sn}_{3} \mathrm{O}_{4}+\mathrm{O}_{2} \\
& 2 \mathrm{Sn}_{3} \mathrm{O}_{4} \rightarrow 6 \mathrm{SnO}+\mathrm{O}_{2}
\end{aligned}
$$

As mentioned before, $\mathrm{Sn}^{2+}$ ions initially reacts with $\mathrm{H}_{2} \mathrm{O}$ to give the hydroxide intermediate $\mathrm{Sn}_{6} \mathrm{O}_{4}(\mathrm{OH})_{4}$, which is favored after subsequent adequate addition of $\mathrm{NH}_{3} \cdot \mathrm{H}_{2} \mathrm{O}$ (reaction i). During hydrothermal treatment (high temperature and high pressure), 
the solution-air interfaces are enormously expanded during boiling conditions and the exposure to oxygen becomes much higher than at ambient conditions. Thus, the divalent $\mathrm{Sn}^{2+}$ ions easily undergo an oxidation to give tetravalent $\mathrm{Sn}^{4+}$ ions in the form of $\mathrm{SnO}_{2}$ (reaction ii) until all $\mathrm{Sn}$ (II) transformed into $\mathrm{Sn}(\mathrm{IV})$ (most likely after $6 \mathrm{~h}$ reaction). This process is substantially following an "oriented attachment" mechanism. The preformed crystalline and amorphous $\mathrm{Sn}_{6} \mathrm{O}_{4}(\mathrm{OH})_{4}$ particles first produce randomly oriented $\mathrm{SnO}_{2}$ NPs. They further go through consecutive rotations in 3-dimensional space as well as interfacial relaxations so as to achieve full fusion. The water/ethanol mixture solvent and $\mathrm{NH}_{3} \cdot \mathrm{H}_{2} \mathrm{O}$ additive play important roles here to control the crystal habits and the NPs surface energies, so that 2-dimensional $\mathrm{SnO}_{2} \mathrm{NSs}$ are produced. By changing $r$ value or additives, different morphologies of $\mathrm{SnO}_{2}$, e.g., hollow spheres and NPs, could be achieved.

When the reaction time is due, the temperature decreases, leading to a drastic falloff in the gas-solution interface area and exposure to oxygen. The resulting low partial pressure of oxygen $\left(P_{\mathrm{O}}\right)$ no doubt induces reduction processes, giving rise to severe nonstoichiometry of $\mathrm{SnO}_{2}$. To avoid large-scale intense deviation from $\mathrm{SnO}_{2}$ stoichiometry, fast cooling using ice-water bath is an effective way. However, it is worthwhile mentioning that no matter how fast the system (e.g., sample SA3) cools down; trivial $\mathrm{Sn}_{3} \mathrm{O}_{4}$ inevitably exist in the final products apart from $\mathrm{SnO}_{2} \mathrm{NSs}$ (reaction iii). In addition, based on SEM images in Figure 9 and reaction iii, the as-formed $\mathrm{SnO}$ plates must be deduced by in situ dissolution of randomly oriented $\mathrm{Sn}_{3} \mathrm{O}_{4}$ intermediate and recrystallization in a highly aligned way (reaction iv). This procedure also features an oriented attachment growth mode. In attempts to avoid the nonstoichiometry of $\mathrm{SnO}_{2}$, we have tried some methods, either bringing in tetravalent $\mathrm{Sn}(\mathrm{IV})$ of $\mathrm{SnCl}_{4} \cdot 5 \mathrm{H}_{2} \mathrm{O}$ (SA14) as precursor or adding tiny amount of $\mathrm{H}_{2} \mathrm{O}_{2}(50 \mu \mathrm{L}, 30 \mathrm{wt} \%)$ (SA15) on the basis of $\mathrm{SA} 3$ configuration. Under alkali condition, $\mathrm{Sn}^{4+}$ reacts with $\mathrm{OH}^{-}$to form small $\mathrm{Sn}(\mathrm{OH})_{4}$ particles as the nucleus, which is then easily transformed into $\mathrm{SnO}_{2} \mathrm{NPs}$ without any production of $\mathrm{SnO}_{2} \mathrm{NSs}$. On the other hand, addition of $\mathrm{H}_{2} \mathrm{O}_{2}$ provides excess oxygen, resulting in harsher pressure relative to that in sample SA3 and thus also yielding $\mathrm{SnO}_{2} \mathrm{NPs}$ (see Supporting Information, Figure S12). From this viewpoint, it appears that inherent nonstoichiometry of $\mathrm{SnO}_{2} \mathrm{NSs}$ is unavoidable in this system. In view that p-type $\mathrm{SnO}$ and n-type $\mathrm{SnO}_{2}$ can form $\mathrm{p}-\mathrm{n}$ junctions to realize enhanced sensor responses, ${ }^{97}$ this work may open alternative routes to the fundamental investigations of tin oxides, their intertransition processes, and the fabrication of novel functional devices.

Lithium-Ion Battery Performance of $\mathrm{SnO}_{2}$ Ultrathin NSs. During the past decade, $\mathrm{SnO}_{2}$ was one of the most extensively investigated materials in lithium-ion batteries (LIB) owing to its potential applications in next-generation anode materials. Its theoretical capacity was estimated to be $782 \mathrm{mAh} /$ $\mathrm{g}$, which is more than twice that of commercially applied graphite $(372 \mathrm{mAh} / \mathrm{g})$. The possible reaction mechanism of $\mathrm{SnO}_{2} / \mathrm{Li}$ cell was proposed as follows: $:^{99-101}$

$$
\begin{aligned}
& \mathrm{SnO}_{2}+4 \mathrm{Li}^{+}+4 \mathrm{e}^{-} \rightarrow \mathrm{Sn}+3 \mathrm{Li}_{2} \mathrm{O} \\
& \mathrm{Sn}+x \mathrm{Li}^{+}+x \mathrm{e}^{-} \rightarrow \mathrm{Li}_{x} \mathrm{Sn} \quad(0 \leq x \leq 4.4)
\end{aligned}
$$

The former reaction is thought to be irreversible with the formation of electrochemically inactive $\mathrm{Li}_{2} \mathrm{O}$ together with partial formation of a solid electrolyte interface (SEI). This irreversible process is responsible for the severe capacity fading in the first few cycles. In contrast, the second reaction is reversible, with repeated alloying and dealloying between $\mathrm{Sn}$ and $\mathrm{Li}$ ions. However, the application of $\mathrm{SnO}_{2}$-based anode materials was somehow impeded by poor capacity retention over long-term cycles. The fast capacity deterioration is mainly ascribed to large stress-induced breakdown of conduction pathways. To relieve this problem, it is suggested that $\mathrm{SnO}_{2}$ should be in a nanometer-sized frame to shorten the diffusion pathway of $\mathrm{Li}$ ions, ${ }^{102,103}$ be highly conducting to promote lithium insertion/extraction, ${ }^{104}$ and possess interior hollow spaces to accommodate large volume change. ${ }^{46,85-87,105}$

Figure 10a shows a representative cyclic voltammograms (CV) of $\mathrm{SnO}_{2} \mathrm{NSs}$ (sample SA3), and the CV behavior is generally consistent with previous reports. ${ }^{85}$ Specifically in the first cycle, two current peaks located at 0.8 and $0.03 \mathrm{~V}$ (cathodic) correspond to the formation of $\mathrm{Li}_{2} \mathrm{O}$ and $\mathrm{Li}_{x} \mathrm{Sn}$, respectively. The anodic potential at $0.6 \mathrm{~V}$ indicates the reversible dealloying process. It should be noted that a broad cathodic peak $(0.8-1.2 \mathrm{~V})$ and a corresponding anodic peak $(1.1-1.6 \mathrm{~V})$ still exist during the fifth cycle, suggesting partial reversibility of reaction $v$. Note here, it has indeed been found that for the metallic $\mathrm{Sn}$ particles larger than $30 \mathrm{~nm}$, the partial electrochemical reversibility of $\mathrm{Li}_{2} \mathrm{O}$ is unable to activate. ${ }^{106-108}$ However, Poizot et al. studied the electrochemical properties of several transition metal oxides for the cathode materials and revealed the partial reversibility of $\mathrm{Li}_{2} \mathrm{O}$ when applied nanosized particles $(10-20 \mathrm{~nm})$ with large surface areas. ${ }^{109}$ And this conclusion was further supported by Chang et al. in the $\mathrm{SnO}_{2}$ nanocrystalline cathode system. ${ }^{110}$ Besides, the partial reversibility of reaction $\mathrm{v}$ is also widely suggested in the recent literatures of $\mathrm{SnO}_{2}$ systems. ${ }^{111-115}$ On this basis, we believe that the observed partial reversibility of reaction $\mathrm{v}$ is due to the ultrathin thickness of $\mathrm{SnO}_{2}$ NSs. Figure $10 \mathrm{~b}$ shows the chargedischarge voltage profile of $\mathrm{SnO}_{2} \mathrm{NSs}$ sample measured at a constant current rate of $0.2 \mathrm{C}(156 \mathrm{~mA} / \mathrm{g})$. In agreement with its $\mathrm{CV}$ behavior, two poorly defined plateau regions ( 0.9 and $0.25 \mathrm{~V}$ ) can be identified in the first discharge process, and it gives a very high discharge capacity of $1742 \mathrm{mAh} / \mathrm{g}$. The following charge process features a charge capacity of 762 $\mathrm{mAh} / \mathrm{g}$, contributing to a low Coulombic efficiency of $43.7 \%$. This large initial capacity loss $(\sim 56 \%)$ is common for $\mathrm{SnO}_{2}$ materials, which is mainly owing to the first irreversible reactions. The discharge and charge capacities in the second cycle are 936 and $872 \mathrm{mAh} / \mathrm{g}$, respectively, resulting in an increased efficiency value of $93.2 \%$. Moreover, the efficiency further increases up to $97.0 \%$ in the fifth cycle and keeps increasing in the following cycles. The actual capacity of $\mathrm{SnO}_{2}$ NSs is clearly higher than its theoretical value $(782 \mathrm{mAh} / \mathrm{g})$ in the first few cycles. This phenomenon also suggests that the reaction $\mathrm{v}$ is partially reversible. Figure 10c displays the comparative performances among $\mathrm{SnO}_{2}$ NSs (SA3, BET surface area $180.3 \mathrm{~m}^{2} / \mathrm{g}$ ), hollow spheres (SA9, BET surface area $101.8 \mathrm{~m}^{2} / \mathrm{g}$ ), and NPs (SA10, BET surface area $199.7 \mathrm{~m}^{2}$ / g). It is evident that $\mathrm{SnO}_{2} \mathrm{NSs}$ manifest a greatly enhanced lithium storage capability as compared to the two counterparts. After 50 discharge and charge cycles, a much higher reversible capacity of $534 \mathrm{mAh} / \mathrm{g}$ was delivered by $\mathrm{SnO}_{2} \mathrm{NSs}$, while the two counterparts only give 355 and $177 \mathrm{mAh} / \mathrm{g}$, respectively. Moreover, the reversible capacity retention reached $68 \%$ for $\mathrm{SnO}_{2}$ NSs. This greatly enhanced storage capacity is mainly due to the ultrathin thicknesses and the unique porous structures: the nanometer-sized networks provide negligible diffusion 
times of ions and probably faster phase transitions, and the "breathable" interior spaces can effectively buffer drastic volume changes during the reactions. Nonetheless, in spite of this obvious advantage over its counterparts, we still believe that the performance of the $\mathrm{SnO}_{2} \mathrm{NSs}$ synthesized here can be improved. Lou et al. demonstrated that significant improvements in the cycle life of $\mathrm{SnO}_{2}$-based anode could be readily achieved by carbon coating. ${ }^{11,112,116-118}$ Thus, more studies are planned in the future.

\section{CONCLUSIONS}

In summary, large-scale and highly pure ultrathin $\mathrm{SnO}_{2} \mathrm{NSs}$ have been successfully prepared by a simple chemical method, which were characterized by XRD, TEM, SEM, HRTEM, XPS, $\mathrm{AFM}$, and UV-vis. It was found that $\mathrm{SnO}_{2} \mathrm{NSs}$ growth follows the "oriented attachment" mode. AFM height profile and HRTEM cross-section images showed a minimum thickness of $\sim 2.1 \mathrm{~nm}$, contributing to large quantum confinement in the thickness directions. The effects of reaction time, solvent, additive, precursor concentration, and cooling rate effect were systematically mapped. Inherent nonstoichiometry was straightforwardly observed in HRTEM images. Finally, lithium-ion storage behaviors of the $\mathrm{SnO}_{2}$ NSs together with $\mathrm{SnO}_{2}$ hollow spheres and NPs were studied. The results showed enhanced performance of $\mathrm{SnO}_{2} \mathrm{NSs}$ sample as compared to its two counterparts. This superior performance is directly brought by faster ion diffusions and better stability owing to the ultrathin thicknesses as well as the unique porous structures. The overall findings in this paper will shed new light on the fundamental properties of tin oxides, and on rational fabrication of new functional devices.

\section{ASSOCIATED CONTENT}

\section{S Supporting Information}

Additional XRD data; TEM and SEM images. This material is available free of charge via the Internet at http://pubs.acs.org.

\section{AUTHOR INFORMATION}

\section{Corresponding Author}

*E-mail: jiangjz@zju.edu.cn.

\section{ACKNOWLEDGMENTS}

Financial support from the National Natural Science Foundation of China (Grants 51071141, 50920105101, 51050110136, 10979002, 60876002, 50890174, 10804096, and 10904127), Zhejiang University-Helmholtz cooperation fund, the Ministry of Education of China (Program for Changjiang Scholars and Scholarship Award for Excellent Doctoral Student), Zhejiang Innovation Program for Graduates (YK2010003), and the Department of Science and Technology of Zhejiang Province is gratefully acknowledged.

\section{REFERENCES}

(1) Novoselov, K. S.; Geim, A. K.; Morozov, S. V.; Jiang, D.; Zhang, Y.; Dubonos, S. V.; Grigorieva, I. V.; Firsov, A. A. Science 2004, 306, 666-669.

(2) Geim, A. K.; Novoselov, K. S. Nature Mater. 2007, 6, 183-191.

(3) Yoo, E.; Kim, J.; Hosono, E.; Zhou, H.-s.; Kudo, T.; Honma, I. Nano Lett. 2008, 8, 2277-2282.

(4) Sasaki, T.; Ebina, Y.; Tanaka, T.; Harada, M.; Watanabe, M.; Decher, G. Chem. Mater. 2001, 13, 4661-4667.

(5) Omomo, Y.; Sasaki, T.; Wang; Watanabe, M. J. Am. Chem. Soc. 2003, 125, 3568-3575.
(6) Hosono, E.; Fujihara, S.; Honma, I.; Zhou, H. Adv. Mater. 2005, 17, 2091-2094.

(7) Novoselov, K. S.; Jiang, D.; Schedin, F.; Booth, T. J.; Khotkevich, V. V.; Morozov, S. V.; Geim, A. K. Proc. Natl. Acad. Sci. U. S. A. 2005, $102,10451-10453$.

(8) Han, X. G.; Kuang, Q.; Jin, M. S.; Xie, Z. X.; Zheng, L. S. J. Am. Chem. Soc. 2009, 131, 3152-3153.

(9) Altuntasoglu, O.; Matsuda, Y.; Ida, S.; Matsumoto, Y. Chem. Mater. 2010, 22, 3158-3164.

(10) Golberg, D.; Bando, Y.; Huang, Y.; Terao, T.; Mitome, M.; Tang, C.; Zhi, C. ACS Nano 2010, 4, 2979-2993.

(11) Vaughn Ii, D. D.; Patel, R. J.; Hickner, M. A.; Schaak, R. E. J. Am. Chem. Soc. 2010, 132, 15170-15172.

(12) Zhang, D. F.; Sun, L. D.; Jia, C. J.; Yan, Z. G.; You, L. P.; Yan, C. H. J. Am. Chem. Soc. 2005, 127, 13492-13493.

(13) Wang, W. W.; Zhu, Y. J.; Yang, L. X. Adv. Funct. Mater. 2007, 17, 59-64.

(14) Fei, J. B.; Cui, Y.; Yan, X. H.; Qi, W.; Yang, Y.; Wang, K. W.; He, Q.; Li, J. B. Adv. Mater. 2008, 20, 452-456.

(15) Yella, A.; Tahir, M. N.; Meuer, S.; Zentel, R.; Berger, R.; Panthofer, M.; Tremel, W. J. Am. Chem. Soc. 2009, 131, 17566-17575.

(16) Penn, R. L.; Banfield, J. F. Science 1998, 281, 969-971.

(17) Banfield, J. F.; Welch, S. A.; Zhang, H. Z.; Ebert, T. T.; Penn, R. L. Science 2000, 289, 751-754.

(18) Narayanaswamy, A.; Xu, H. F.; Pradhan, N.; Kim, M.; Peng, X. G. J. Am. Chem. Soc. 2006, 128, 10310-10319.

(19) Portehault, D.; Cassaignon, S.; Baudrin, E.; Jolivet, J. P. J. Mater. Chem. 2009, 19, 7947-7954.

(20) Kim, Y. H.; Lee, J. H.; Shin, D. W.; Park, S. M.; Moon, J. S.; Nam, J. G.; Yoo, B. Chem. Commun. 2010, 46, 2292-2294.

(21) Koh, W. K.; Bartnik, A. C.; Wise, F. W.; Murray, C. B. J. Am. Chem. Soc. 2010, 132, 3909-3913.

(22) Yuwono, V. M.; Burrows, N. D.; Soltis, J. A.; Penn, R. L. J. Am. Chem. Soc. 2010, 132, 2163-2165.

(23) Chen, J. S.; Zhu, T.; Li, C. M.; Lou, X. W. Angew. Chem., Int. Ed. 2011, 50, 650-653.

(24) Colfen, H.; Mann, S. Angew. Chem., Int. Ed. 2003, 42, 23502365.

(25) Colfen, H.; Antonietti, M. Angew. Chem., Int. Ed. 2005, 44, $5576-5591$

(26) Pan, Z. W.; Dai, Z. R.; Wang, Z. L. Science 2001, 291, 19471949.

(27) Cheng, B.; Russell, J. M.; Shi, W. S.; Zhang, L.; Samulski, E. T. J. Am. Chem. Soc. 2004, 126, 5972-5973.

(28) Liu, Y.; Dong, H.; Liu, M. L. Adv. Mater. 2004, 16, 353-356.

(29) Ba, J. H.; Polleux, J.; Antonietti, M.; Niederberger, M. Adv. Mater. 2005, 17, 2509-2512.

(30) Wang, Y.; Zeng, H. C.; Lee, J. Y. Adv. Mater. 2006, 18, 645-649.

(31) Lou, X. W.; Yuan, C. L.; Archer, L. A. Adv. Mater. 2007, 19, $3328-3332$.

(32) Meduri, P.; Pendyala, C.; Kumar, V.; Sumanasekera, G. U.; Sunkara, M. K. Nano Lett. 2009, 9, 612-616.

(33) Leite, E. R.; Weber, I. T.; Longo, E.; Varela, J. A. Adv. Mater. 2000, 12, 965-968.

(34) Pinna, N.; Neri, G.; Antonietti, M.; Niederberger, M. Angew. Chem., Int. Ed. 2004, 43, 4345-4349.

(35) Kolmakov, A.; Klenov, D. O.; Lilach, Y.; Stemmer, S.; Moskovits, M. Nano Lett. 2005, 5, 667-673.

(36) Kuang, Q.; Lao, C. S.; Wang, Z. L.; Xie, Z. X.; Zheng, L. S. J. Am. Chem. Soc. 2007, 129, 6070-6071.

(37) Han, X. G.; Jin, M. S.; Xie, S. F.; Kuang, Q.; Jiang, Z. Y.; Jiang, Y. Q.; Xie, Z. X.; Zheng, L. S. Angew. Chem., Int. Ed. 2009, 48, 91809183.

(38) Ogale, S. B.; Choudhary, R. J.; Buban, J. P.; Lofland, S. E.; Shinde, S. R.; Kale, S. N.; Kulkarni, V. N.; Higgins, J.; Lanci, C.; Simpson, J. R.; Browning, N. D.; Das Sarma, S.; Drew, H. D.; Greene, R. L.; Venkatesan, T. Phys. Rev. Lett. 2003, 91, 077205.

(39) Sundaresan, A.; Bhargavi, R.; Rangarajan, N.; Siddesh, U.; Rao, C. N. R. Phys. Rev. B 2006, 74, 161306. 
(40) Niu, M.; Huang, F.; Cui, L.; Huang, P.; Yu, Y.; Wang, Y. ACS Nano 2010, 4, 681-688.

(41) Reddy, A. L. M.; Ramaprabhu, S. J. Phys. Chem. C 2007, 111, $7727-7734$.

(42) Selvan, R. K.; Perelshtein, I.; Perkas, N.; Gedanken, A. J. Phys. Chem. C 2008, 112, 1825-1830.

(43) Yan, J. A.; Khoo, E.; Sumboja, A.; Lee, P. S. ACS Nano 2010, 4, $4247-4255$.

(44) Zhang, Y. L.; Liu, Y.; Liu, M. L. Chem. Mater. 2006, 18, $4643-$ 4646.

(45) Park, M. S.; Wang, G. X.; Kang, Y. M.; Wexler, D.; Dou, S. X.; Liu, H. K. Angew. Chem., Int. Ed. 2007, 46, 750-753.

(46) Park, M. S.; Kang, Y. M.; Wang, G. X.; Dou, S. X.; Liu, H. K. Adv. Funct. Mater. 2008, 18, 455-461.

(47) Paek, S. M.; Yoo, E.; Honma, I. Nano Lett. 2009, 9, 72-75.

(48) Huang, J. Y.; Zhong, L.; Wang, C. M.; Sullivan, J. P.; Xu, W.; Zhang, L. Q.; Mao, S. X.; Hudak, N. S.; Liu, X. H.; Subramanian, A.; Fan, H.; Qi, L.; Kushima, A.; Li, J. Science 2010, 330, 1515-1520.

(49) Wang, C.; Zhou, Y.; Ge, M.; Xu, X.; Zhang, Z.; Jiang, J. Z. J. Am. Chem. Soc. 2010, 132, 46-47.

(50) Wang, C.; Ge, M. Y.; Jiang, J. Z. Appl. Phys. Lett. 2010, 97, 042510 .

(51) Hill, R. J.; Howard, C. J. In Australian Atomic Energy Commission Report M112 AAEC (now ANSTO), Lucas Heights Research Laboratories, NSW Australia, 1986.

(52) Ning, J. J.; Dai, Q. Q.; Jiang, T.; Men, K. K.; Liu, D. H.; Xiao, N. R.; Li, C. Y.; Li, D. M.; Liu, B. B.; Zou, B.; Zou, G. T.; Yu, W. W. Langmuir 2009, 25, 1818-1821.

(53) Ning, J. J.; Jiang, T.; Men, K. K.; Dai, Q. Q.; Li, D. M.; Wei, Y. J.; Liu, B. B.; Chen, G.; Zou, B.; Zou, G. T. J. Phys. Chem. C 2009, 113, 14140-14144.

(54) Chen, J. S.; Tan, Y. L.; Li, C. M.; Cheah, Y. L.; Luan, D. Y.; Madhavi, S.; Boey, F. Y. C.; Archer, L. A.; Lou, X. W. J. Am. Chem. Soc. 2010, 132, 6124-6130.

(55) Choi, M.; Na, K.; Kim, J.; Sakamoto, Y.; Terasaki, O.; Ryoo, R. Nature 2009, 461, 246-U120.

(56) Gu, F.; Wang, S. F.; Lu, M. K.; Zhou, G. J.; Xu, D.; Yuan, D. R. J. Phys. Chem. B 2004, 108, 8119-8123.

(57) Xu, X. X.; Zhuang, J.; Wang, X. J. Am. Chem. Soc. 2008, 130, 12527-12535

(58) Kar, A.; Kundu, S.; Patra, A. J. Phys. Chem. C 2011, 115, 118124.

(59) Warren, B. E.; Averbach, B. L. J. Appl. Phys. 1950, 21, 595-599.

(60) Warren, B. E.; Averbach, B. L. J. Appl. Phys. 1952, 23, 497-497.

(61) Williamson, G. K.; Hall, W. H. Acta Metall. 1953, 1, 22-31.

(62) Ribeiro, C.; Longo, E.; Leite, E. R. Appl. Phys. Lett. 2007, 91, 103105 .

(63) van Huis, M. A.; Kunneman, L. T.; Overgaag, K.; Xu, Q.; Pandraud, G.; Zandbergen, H. W.; Vanmaekelbergh, D. Nano Lett. 2008, 8, 3959-3963.

(64) White, T. A.; Moreno, M. S.; Midgley, P. A. Z. Kristallogr. 2010, $225,56-66$

(65) Tyuliev, G.; Angelov, S. Appl. Surf. Sci. 1988, 32, 381-391.

(66) Naeem, M.; Hasanain, S. K.; Kobayashi, M.; Ishida, Y.; Fujimori, A.; Buzby, S.; Shah, S. I. Nanotechnology 2006, 17, 2675-2680.

(67) Zhang, L.; Ge, S. H.; Zuo, Y. L.; Zhang, B. M.; Xi, L. J. Phys. Chem. C 2010, 114, 7541-7547.

(68) Maestre, D.; Ramirez-Castellanos, J.; Hidalgo, P.; Cremades, A.; Gonzalez-Calbet, J. M.; Piqueras, J. Eur. J. Inorg. Chem. 2007, 15441548.

(69) Seko, A.; Togo, A.; Oba, F.; Tanaka, I. Phys. Rev. Lett. 2008, 100, 045702.

(70) Godinho, K. G.; Walsh, A.; Watson, G. W. J. Phys. Chem. C 2009, 113, 439-448.

(71) Themlin, J. M.; Chtaib, M.; Henrard, L.; Lambin, P.; Darville, J.; Gilles, J. M. Phys. Rev. B 1992, 46, 2460-2466.

(72) Ahn, H. J.; Choi, H. C.; Park, K. W.; Kim, S. B.; Sung, Y. E. J. Phys. Chem. B 2004, 108, 9815-9820.
(73) Ramgir, N. S.; Mulla, I. S.; Vijayamohanan, K. P. J. Phys. Chem. B 2005, 109, 12297-12303.

(74) Zhao, Q. R.; Xie, Y.; Dong, T.; Zhang, Z. G. J. Phys. Chem. C 2007, 111, 11598-11603.

(75) Zhang, Z. Y.; Shao, C. L.; Li, X. H.; Zhang, L.; Xue, H. M.; Wang, C. H.; Liu, Y. C. J. Phys. Chem. C 2010, 114, 7920-7925.

(76) Chandra, D.; Mukherjee, N.; Mondal, A.; Bhaumik, A. J. Phys. Chem. C 2008, 112, 8668-8674.

(77) Jia, T.; Wang, W.; Long, F.; Fu, Z.; Wang, H.; Zhang, Q. J. Phys. Chem. C 2009, 113, 9071-9077.

(78) Butler, M. A. J. Appl. Phys. 1977, 48, 1914-1920.

(79) Lin, H.; Huang, C. P.; Li, W.; Ni, C.; Shah, S. I.; Tseng, Y. H. Appl. Catal., B 2006, 68, 1-11.

(80) Brus, L. E. J. Chem. Phys. 1984, 80, 4403-4409.

(81) Brus, L. J. Phys. Chem. 1986, 90, 2555-2560.

(82) Catlow, C. R. A.; James, R. Nature 1978, 272, 603-605.

(83) Zhu, H. L.; Yang, D. R.; Yu, G. X.; Zhang, H.; Yao, K. H. Nanotechnology 2006, 17, 2386-2389.

(84) Xi, G.; Ye, J. Inorg. Chem. 2010, 49, 2302-2309.

(85) Lou, X. W.; Wang, Y.; Yuan, C. L.; Lee, J. Y.; Archer, L. A. Adv. Mater. 2006, 18, 2325-2329.

(86) Lou, X. W.; Yuan, C. L.; Archer, L. A. Small 2007, 3, 261-265.

(87) Demir-Cakan, R.; Hu, Y. S.; Antonietti, M.; Maier, J.; Titirici, M. M. Chem. Mater. 2008, 20, 1227-1229.

(88) Puntes, V. F.; Krishnan, K. M.; Alivisatos, A. P. Science 2001, 291, 2115-2117.

(89) Chen, X.; Sun, X.; Li, Y. Inorg. Chem. 2002, 41, 4524-4530.

(90) Dong, A. G.; Ren, N.; Tang, Y.; Wang, Y. J.; Zhang, Y. H.; Hua, W. M.; Gao, Z. J. Am. Chem. Soc. 2003, 125, 4976-4977.

(91) Gu, Q.; Nagai, K.; Norimatsu, T.; Fujioka, S.; Nishimura, H.; Nishihara, K.; Miyanaga, N.; Izawa, Y. Chem. Mater. 2005, 17, 11151122.

(92) Grubbs, R. B. Nature Mater. 2007, 6, 553-555.

(93) Tong, H.; Zhu, Y. J.; Yang, L. X.; Li, L.; Zhang, L.; Chang, J.; An, L. Q.; Wang, S. W. J. Phys. Chem. C 2007, 111, 3893-3900.

(94) Yang, H. G.; Sun, C. H.; Qiao, S. Z.; Zou, J.; Liu, G.; Smith, S. C.; Cheng, H. M.; Lu, G. Q. Nature 2008, 453, 638-U4.

(95) Xiao, X.; Zhang, W.-D. J. Mater. Chem. 2010, 20, 5866-5870.

(96) Xu, X. B.; Ge, M. Y.; Stahl, K.; Jiang, J. Z. Chem. Phys. Lett. 2009, 482, 287-290.

(97) Kresse, G.; Furthmuller, J. Phys. Rev. B 1996, 54, 11169-11186.

(98) Pan, X. Q.; Fu, L. J. Appl. Phys. 2001, 89, 6048-6055.

(99) Courtney, I. A.; Dahn, J. R. J. Electrochem. Soc. 1997, 144, 20452052.

(100) Brousse, T.; Retoux, R.; Herterich, U.; Schleich, D. M. J. Electrochem. Soc. 1998, 145, 1-4.

(101) Courtney, I. A.; McKinnon, W. R.; Dahn, J. R. J. Electrochem. Soc. 1999, 146, 59-68.

(102) Guo, Y. G.; Hu, Y. S.; Sigle, W.; Maier, J. Adv. Mater. 2007, 19, 2087-2091.

(103) Hassoun, J.; Panero, S.; Simon, P.; Taberna, P. L.; Scrosati, B. Adv. Mater. 2007, 19, 1632-1635.

(104) Chen, G.; Wang, Z. Y.; Xia, D. G. Chem. Mater. 2008, 20, 6951-6956.

(105) Ding, S.; Chen, J. S.; Qi, G.; Duan, X.; Wang, Z.; Giannelis, E. P.; Archer, L. A.; Lou, X. W. J. Am. Chem. Soc. 2011, 133, 21-23.

(106) Kim, Y. I.; Moon, H.-S.; Ji, K. S.; Seong, S. H.; Park, J.-W. J. Power Sources 2001, 101, 253-258.

(107) Kim, J. Y.; King, D. E.; Kumta, P. N.; Blomgren, G. E. J. Electrochem. Soc. 2000, 147, 4411-4420.

(108) Nam, S. C.; Yoon, Y. S.; Cho, B. W.; Chun, H. S.; Yun, K. S. J. Electrochem. Soc. 2001, 148, A220-A223.

(109) Poizot, P.; Laruelle, S.; Grugeon, S.; Dupont, L.; Tarascon, J.M. Nature 2000, 407, 496-499.

(110) Chang, S. T.; Leu, I. C.; Liao, C. L.; Yen, J. H.; Hon, M. H. J. Mater. Chem. 2004, 14, 1821-1826.

(111) Chen, J. S.; Cheah, Y. L.; Chen, Y. T.; Jayaprakash, N.; Madhavi, S.; Yang, Y. H.; Lou, X. W. J. Phys. Chem. C 2009, 113, 20504-20508. 
(112) Lou, X. W.; Chen, J. S.; Chen, P.; Archer, L. A. Chem. Mater. 2009, 21, 2868-2874.

(113) Chen, Y.; Huang, Q. Z.; Wang, J.; Wang, Q.; Xue, J. M. J. Mater. Chem. 2011, 21, 17448-17453.

(114) Wu, P.; Du, N.; Zhang, H.; Zhai, C.; Yang, D. ACS Appl. Mater. Interfaces 2011, 3, 1946-1952.

(115) Ding, S.; Chen, J. S.; Lou, X. W. Chem.-Asian J. 2011, 6, $2278-2281$.

(116) Lou, X. W.; Deng, D.; Lee, J. Y.; Archer, L. A. Chem. Mater. 2008, 20, 6562-6566.

(117) Lou, X. W.; Li, C. M.; Archer, L. A. Adv. Mater. 2009, 21, 2536-2539.

(118) Ding, S.; Luan, D.; Boey, F. Y. C.; Chen, J. S.; Lou, X. W. Chem. Commun. 2011, 47, 7155-7157.

(119) Wang, C.; Wu, Q.; Ge, H. L.; Shang, T.; Jiang, J. Z. Nanotechnology 2012, 23, 075704. 